\title{
Role of Primate Cerebellar Hemisphere in Voluntary Eye Movement Control Revealed by Lesion Effects
}

\author{
Masafumi Ohki, ${ }^{1,2}$ Hiromasa Kitazawa, ${ }^{2}$ Takahito Hiramatsu, ${ }^{3}$ Kimitake Kaga, ${ }^{1}$ Taiko Kitamura, ${ }^{4}$ \\ Jinzo Yamada, ${ }^{4}$ and Soichi Nagao ${ }^{2,5}$ \\ ${ }^{1}$ Department of Otorhinolaryngology, Graduate School of Medicine, University of Tokyo, Tokyo; ${ }^{2}$ Laboratory for Motor Learning Control, \\ RIKEN Brain Science Institute, Saitama; ${ }^{3}$ Department of Neurosurgery, Jichi Medical University, Tochigi; ${ }^{4}$ Laboratory of Histology \\ and Neuroanatomy, Tokyo Medical University, Tokyo; and ${ }^{5}$ Solution-Oriented Research for Science and Technology, Japan Science \\ and Technology Corporation, Saitama, Japan
}

Submitted 4 April 2008; accepted in final form 20 October 2008

\begin{abstract}
Okhi M, Kitazawa H, Hiramatsu T, Kaga K, Kitamura T, Yamada J, Nagao S. Role of primate cerebellar hemisphere in voluntary eye movement control revealed by lesion effects. $J$ Neurophysiol 101: 934-947, 2009. First published October 29, 2008; doi:10.1152/jn.90440.2008. The anatomical connection between the frontal eye field and the cerebellar hemispheric lobule VII (H-VII) suggests a potential role of the hemisphere in voluntary eye movement control. To reveal the involvement of the hemisphere in smooth pursuit and saccade control, we made a unilateral lesion around H-VII and examined its effects in three Macaca fuscata that were trained to pursue visually a small target. To the step $\left(3^{\circ}\right)$-ramp $\left(5-20^{\circ} / \mathrm{s}\right)$ target motion, the monkeys usually showed an initial pursuit eye movement at a latency of $80-140 \mathrm{~ms}$ and a small catch-up saccade at $140-220$ ms that was followed by a postsaccadic pursuit eye movement that roughly matched the ramp target velocity. After unilateral cerebellar hemispheric lesioning, the initial pursuit eye movements were impaired, and the velocities of the postsaccadic pursuit eye movements decreased. The onsets of $5^{\circ}$ visually guided saccades to the stationary target were delayed, and their amplitudes showed a tendency of increased trial-to-trial variability but never became hypo- or hypermetric. Similar tendencies were observed in the onsets and amplitudes of catch-up saccades. The adaptation of open-loop smooth pursuit velocity, tested by a step increase in target velocity for a brief period, was impaired. These lesion effects were recognized in all directions, particularly in the ipsiversive direction. A recovery was observed at 4 wk postlesion for some of these lesion effects. These results suggest that the cerebellar hemispheric region around lobule VII is involved in the control of smooth pursuit and saccadic eye movements.
\end{abstract}

\section{N T R O D U C T I O N}

Precise eye movements play an important role in both postural and movement control. The vestibuloocular reflex and optokinetic eye movement response play a major role in stabilizing the visual image during movements of animal. Smooth pursuit and saccade eye movements are utilized to voluntarily fixate on the visual image of the target on the central fovea and play an important role in visually guided limb movements in the primate. These eye movements are considered to be under learning control by the brain. Several cerebral and cerebellar areas are known to be involved in the control of smooth pursuit and saccades (e.g., Leigh and Zee 2006). Ablation, chemical inactivation, and electrical stimulation studies in monkeys suggest that the parietal middle temporal

\footnotetext{
Address for reprint requests and other correspondence: S. Nagao, Laboratory for Motor Learning Control, RIKEN BSI, Hirosawa 2-1, Wako, Saitama, Japan 351-0198 (E-mail: nagaos@brain.riken.jp).
}

(MT) and medial superior temporal (MST) areas (e.g., Newsome et al. 1985) and the frontal eye field (FEF) (Bruce and Goldberg 1985; Bruce et al. 1985; Keating 1991; Keating et al. 1996; Lynch 1987; Shi et al. 1998) are the important cerebral areas for smooth pursuit and saccades. Lesion studies in monkeys suggest that the flocculus-paraflocculus complex (Hiramatsu et al. 2008; Rambold et al. 2002; Zee et al. 1981) and vermal lobule VI/VIIA (Barash et al. 1999; Takagi et al. 1998, 2000) are the relevant cerebellar areas. Moreover, lesions in the vermal lobule VI/VIIA impaired the adaptation of saccade amplitude induced by double step paradigms (Barash et al. 1999; Takagi et al. 1998). Single-unit recording experiments revealed the presence of smooth pursuit- or saccaderelated neurons in the flocculus-paraflocculus complex (Lisberger and Fuchs 1978; Miles et al. 1981; Nagao 1992; Noda and Mikami 1986; Shidara and Kawano 1993; Stone and Lisberger 1990) and vermal lobule VI/VIIA (Kase et al. 1980; Ohtsuka and Noda 1995; Sato and Noda 1992; Suzuki et al. 1981; Thier et al. 2000). However, these cerebellar areas belong to phylogenetically older areas of the cerebellum (Robinson and Fuchs 2001; Voogd and Barmack 2006).

Several recent clinical reports have suggested a possible involvement of the cerebellar hemisphere in the control of smooth pursuit and saccades (Leigh and Zee 2006). Patients with unilateral hemispheric infarction sparing the cerebellar nuclei showed deficits in smooth pursuit eye movements (Straube et al. 1997). Several functional MRI studies revealed an elevation of blood-oxygen-level-dependent (BOLD) activity in the hemisphere during saccades (Hayakawa et al. 2002), optokinetic stimulation (Dieterich et al. 2000), and smooth pursuit in the presence of optokinetic stimulation (Lindner et al. 2006). Saccade-related neural activity was reported in the monkey cerebellar hemisphere (Marple-Horvat and Stein 1990; Mano et al. 1991, 1996). Results of our previous anatomical study on monkeys suggest that the cerebellar hemispheric lobule VII receives mossy fiber inputs issued from the FEF through the pontine nuclei and nucleus reticularis tegmenti pontis and projects to the oculomotor-related cerebellar nuclear areas (Xiong et al. 2002). These reports consistently indicate that the cerebellar hemisphere may play a role in the control of smooth pursuit and saccades. Here, to reveal the possible role of the cerebellar hemisphere in smooth pursuit and saccade

\footnotetext{
The costs of publication of this article were defrayed in part by the payment of page charges. The article must therefore be hereby marked "advertisement" in accordance with 18 U.S.C. Section 1734 solely to indicate this fact.
} 
control, we made unilateral lesions in the hemispheric lobule VII in monkeys and examined its effects on the dynamic characteristics and adaptability of the eye movements evoked by step-ramp target motion. Parts of the present study were reported in abstract form (Ohki et al. 2003).

\section{METHODS}

\section{Preparation of animals}

Two male and one female Macaca fuscata (5.5-7 kg body wt) were used (M1-M3). Under general anesthesia by intravenous administration of $40 \mathrm{mg} / \mathrm{kg}$ (body weight) pentobarbital sodium (Nembutal, Dainippon-Sumitomo Pharma, Tokyo, Japan) and $10 \mathrm{mg} / \mathrm{kg}$ ketamine (Ketalar, Daiichi-Sankyo, Tokyo, Japan), these monkeys were surgically implanted with six anchor bolts and a holder for head fixation under aseptic conditions. Sclera search coils (Robinson 1963) were also implanted in the left eyes in these monkeys. After a 1-wk recovery period, these monkeys were trained to sit in a chair with their head fixed and to pursue with their eyes a back-projected target spot moving on a translucent screen placed $45 \mathrm{~cm}$ in front for $1-2 \mathrm{~h}$ in a dark room. The red spot (size, $0.2^{\circ}$; brightness, $8 \mathrm{~cd} / \mathrm{cm}^{2}$ ) emitted from a laser diode was projected by two galvanometer-driven mirrors that were controlled by a personal computer system (Physio, PhysioTech, Tokyo, Japan) equipped with an ADDA interface. The time resolution of this system was $1 \mathrm{~ms}$. The monkey was rewarded when it kept its gaze within $1.5^{\circ}$ around the target. Training was continued for $\sim 3$ mo before the monkeys were used for the experiments that lasted for 3-5 mo.

\section{Eye movement measurements}

The real-time horizontal and vertical positions of the left eye were measured by the sclera search coil method (MEL-2, Enzanshi-Kogyo, Tokyo, Japan) and recorded with a personal computer system (PC9821, NEC, Tokyo, Japan) at a sampling rate of $1 \mathrm{kHz}$. The eyeposition signal was calibrated with visually guided saccade tests by requiring the monkey to gaze on a spot presented 5 or $10^{\circ}$ right-, left-, down-, and upward before the start of the daily session. Eye position signals were monitored from -1 to $3 \mathrm{~s}$ around the target jump to determine the correct eye position corresponding to the target. During the session of the smooth pursuit test, the target was presented in the center of the screen at random intervals at an average of $7 \mathrm{~s}$. When the monkey fixated on the target projected on the center for $>0.6 \mathrm{~s}$, the target moved in a step mode (step size, $3^{\circ}$ ) and then moved at a constant velocity $(5-20 \%$ s) to either the left, right, down, or up. Leftor rightward (down- or upward) target movement was tested in a randomly mixed manner with equal probability. The monkeys responded to the target movement with an initial smooth pursuit eye movement and a subsequent catch-up saccade that was followed by the postsaccadic smooth pursuit eye movement (Fig. 1A). The target was extinguished at 250-500 ms after the onset of the catch-up saccade. When the monkeys pursued the target until the extinction of

FIG. 1. Evoked eye movements toward step-ramp moving target. A: eye position traces (Eye) while monkey $M 1$ pursued step $\left(3^{\circ}\right)$-ramp $\left(10^{\circ} / \mathrm{s}\right)$ moving target (Target). $B$ : averaged eye position trace aligned at the onset of target motion. The onset of initial smooth pursuit was estimated by the initial flexion point ( $\mathbf{\Delta})$ after the onset of the target motion in the averaged eye position trace. $C$ : positions of target and eye aligned to the midpoint $(\uparrow)$ of catch-up saccades. The midpoint of the catch-up saccade (Ts) was defined as the time when the amplitude of the catch-up saccade exceeded $50 \%$ of its mean amplitude. $D$ : averaged eye position trace aligned at the midpoint $(\uparrow)$ of catch-up saccades. The amplitude of the catch-up saccade (CS) was measured on the averaged eye position trace. The velocity of the postsaccadic smooth pursuit (PSP) was calculated by measuring eye positional changes at $60-110 \mathrm{~ms}$ from the midpoint of the catch-up saccade (Ts). E: averaged eye velocity trace calculated from the eye position trace of $C$. the target with an accuracy of $\pm 1.5^{\circ}$, they were rewarded with a drop of apple juice. The zones for reward were shifted to the eye positions that were matched to the impaired pursuit eye velocity with an accuracy of $\pm 1.5^{\circ}$ after hemispheric lesioning. In monkey $M 3$, upward trials were not carried out because he was unskilled in upward pursuit. During each experimental session, the monkeys received 200-300 ml apple juice.
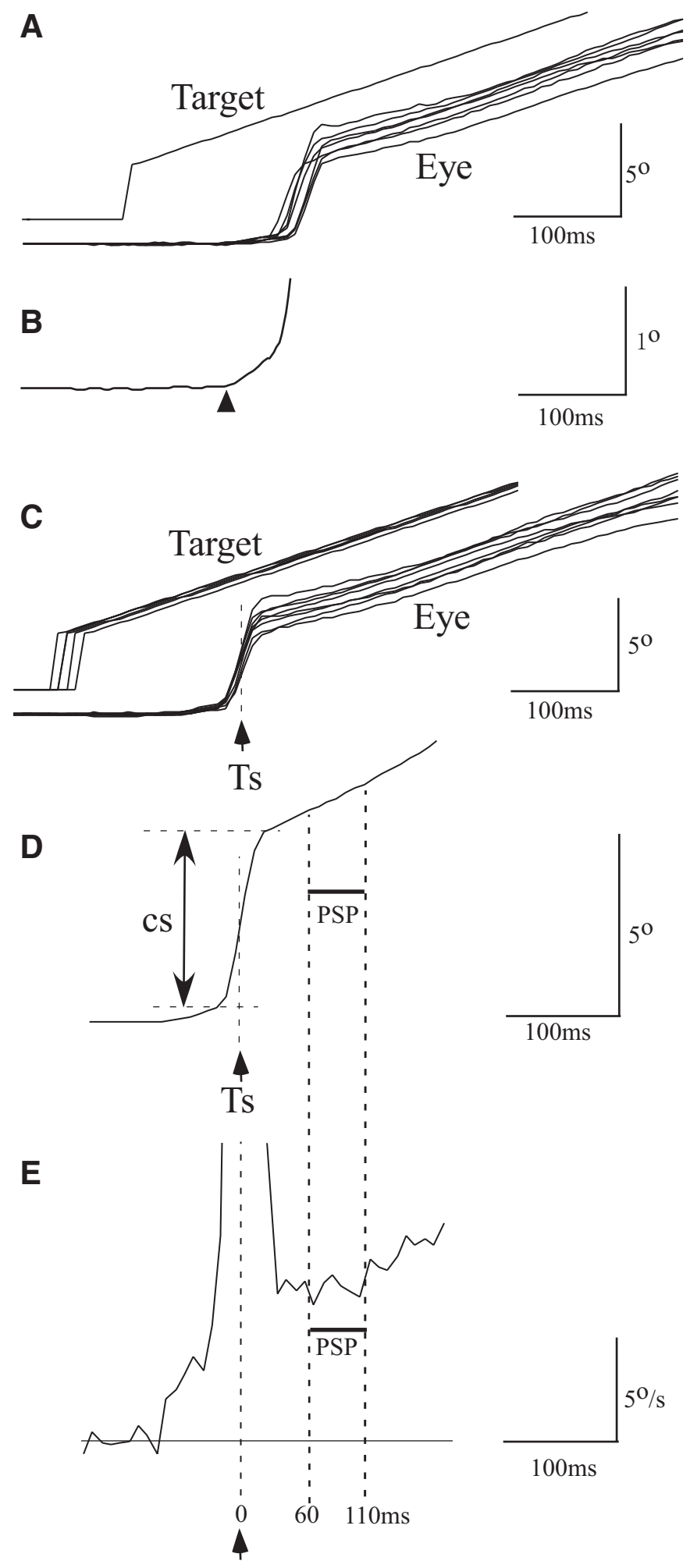

Ts 
To examine the initial smooth pursuit eye movements, eye position traces obtained from 16 trials, free of artifacts due to breaking of pursuit eye movements, were aligned with respect to the onset of target motion (Fig. 1A). The onset of initial smooth pursuit was estimated by the initial flexion point in the averaged eye-position trace by inspection (Fig. 1B). To examine the catch-up saccades and postsaccadic smooth pursuit, eye-position traces obtained from 16 trials were realigned with respect to the midpoint of catch-up saccades (Ts, Fig. $1 C$ ). The postsaccadic smooth pursuit velocity $(\%)$ was calculated as the [(Eye position at $110 \mathrm{~ms}$ after Ts $)-($ Eye position at $60 \mathrm{~ms}$ after Ts) $] / 50 \mathrm{~ms}$. The $60-110 \mathrm{~ms}$ after the midpoint of catch-up saccades was used because the effects from the preceding catch-up saccades and the secondary catch-up saccades on pursuit eye movements were small during this interval (Hiramatsu et al. 2008; Nagao and Kitazawa 1998; Ogawa and Fujita 1997). The amplitude of the catch-up saccade was measured in averaged eye-position traces as shown in Fig. $1 D$. The latency of the catch-up saccade was measured in the eye-position traces aligned with respect to the onset of target motion by inspection (Fig. $1 A$, also see Fig. $3, E-K$ ). Instantaneous eye velocity (Fig. $1 E$ ) was obtained by electrically differentiating eye position signals with the high-pass filter (cut-off frequency, $100 \mathrm{~Hz}$ ). Labview version 6 (National Instruments Japan, Tokyo, Japan) software was used for off-line mathematical analyses. For examining the relationship between the eye movement dynamics and ramp target velocities in a particular direction, first, a velocity of $5 \% \mathrm{~s}$ ramp target was tested for 32 trials, then a velocity of 7.5 or $10 \%$ for another 32 trials, and finally, a velocity of 10,15 , or $20 \%$ s for another 32 trials. These tests were repeated three to seven times for each direction before and after the hemispheric lesioning. We did not test smooth pursuit toward step-back target movements (e.g., Newsome et al. 1985) in this study.

\section{Adaptation paradigm of postsaccadic pursuit eye movements}

Adaptation of postsaccadic pursuit eye movements was examined in the ipsiversive, contraversive, and downward directions by referring to the previous human (Ogawa and Fujita 1997) and monkey (Nagao and Kitazawa 1998) studies. When the monkey fixated for $>0.6 \mathrm{~s}$ on the target presented at the center of the screen, the target was stepped by $3^{\circ}$ and moved at $10 \%$ in either left-, right-, or downward direction. When the amplitude of the catch-up saccade recorded by the personal computer reached $50 \%$ of the mean catch-up saccade amplitude for that monkey, the target velocity was increased to $20 \%$ for $250 \mathrm{~ms}$, and then the target was extinguished. When the monkey pursued the target with an accuracy of $\pm 1.5^{\circ}$, it was rewarded with a drop of apple juice. The zones for reward were shifted to the eye positions that were matched to the impaired pursuit velocity with an accuracy of $\pm 1.5^{\circ}$ after hemispheric lesioning. These trials were presented at random intervals at an average of $7 \mathrm{~s}$. Left- or rightward (down- or upward) pursuit was tested in a randomly mixed manner with equal probability, and target accelerations were presented in only one direction. The postsaccadic pursuit velocities were measured as described in the preceding text. In this study, 16 trials were termed collectively as one block. The mean postsaccadic pursuit velocity was determined from one block. Usually, two blocks were tested for the control, i.e., preadaptation baseline, and 10-12 blocks were given for the adaptation paradigm. The mean postsaccadic pursuit velocity for one block of adaptation paradigm was normalized to the mean postsaccadic pursuit for two control blocks. The control and adaptation experiments for the same direction were carried out for each monkey with an interval of $\geq 3$ days to avoid the possible long-term effects of adaptation that may continue $\leq 24$ h (e.g., Robinson et al. 2006; Shutoh et al. 2006).

\section{Lesioning of cerebellar hemisphere}

Under general anesthesia and aseptic condition, the cranial bone covering the left vermis and hemispheric lobules VI and VII was removed. After sectioning of the dura mater over the vermis and hemisphere, the left hemispheric lobule VII was lesioned by suction under an operating microscope. The defect in the dura mater was covered with an artificial dura mater (Gore-Tex, Gore-Tex Japan, Tokyo, Japan), which was sutured using 6-0 nylon surgical thread in a watertight manner. The defect on the cranial bone was patched with the removed bone, and overlying muscles, fascia, and skin were sutured. After the surgery, antibiotics were given to the monkeys to prevent infection.

After the completion of all the experiments, under deep general anesthesia, the three monkeys were transcardially perfused with saline followed by $10 \%$ buffered formol solution. Their brains were removed, and $60-\mu \mathrm{m}$-thick frozen coronal sections were prepared. The sections were Nissl-stained with $0.1 \%$ cresyl violet for standard histological analysis. The significance of the data were evaluated using a standard statistics package (StatView, version 5, SAS Institute). Most of the pre- and postlesion data and the time course of adaptation of smooth pursuit were assessed by using ANOVA for repeated measurements. All efforts were made to minimize the number of monkeys used and their suffering. These experimental protocols followed the Principles of Laboratory Animal Care (National Institutes of Health Publication No. 80-23, revised in 1996) and were approved by the management committees of RIKEN and Jichi Medical Laboratory of Experimental Medicine.

\section{RES ULTS}

\section{Lesions of left hemispheric lobule}

We made unilateral lesions of the left cerebellar hemisphere in the three monkeys. According to Larsell and Jansen (1970), the cerebellar hemispheric lobule VII (H-VII) is divided into H-VIIA (crus I and II) and H-VIIB (paramedian lobule). In monkey M1, most areas of H-VIIA and H-VIIB were lesioned except for their most medial portions adjacent to the vermal lobuli VI, VIIA, VIIIA, and VIIIB. The caudal area of H-VI (simple lobule) and a small area of rostromedial H-VIIIA adjacent to H-VIIB were also lesioned (Fig. 2, $A-D$ and $K$ ). In monkey M2, most areas of H-VIIA and H-VIIB, a small caudal area of H-VI adjacent to H-VII, and a small area of rostromedial H-VIIIA were lesioned (Fig. 2, $E-G$ and $K$ ). In monkey $M 3$, the caudolateral half area of H-VIIA, the central area of $\mathrm{H}-\mathrm{VIIB}$ and a small area of the rostro-medial H-VIIIA were lesioned, while H-VI was intact (Fig. 2, $H-J$ and $K$ ). Vermis and cerebellar nuclei were intact in all the three monkeys. Thus the lesions covered mainly the H-VIIA and H-VIIB and included the caudal area of H-VI adjacent to H-VII and a small area of rostromedial H-VIIIA (Fig. $2 K$ ).

All the monkeys could hold their gaze without any nystagmic eye movements both before and after lesioning and did not show any gaze-holding difficulties for fixating on the target, except for small slow eye-position drifts seen while they were fixating on the stationary target. These drifts were observed at 1-2 days after lesioning (not shown in figures), and disappeared within 1-3 days. Dynamic characteristics and adaptability of smooth pursuit were tested for 1 mo postlesion after the disappearance of such drifts. We did not systematically examine limb movements after lesioning, but we observed no abnormalities in their daily behaviors, such as postural instability while standing and sitting in the cage, slowness in reaching their left hand for the food tray, or clumsiness in picking up food pellets with their fingers. 
A

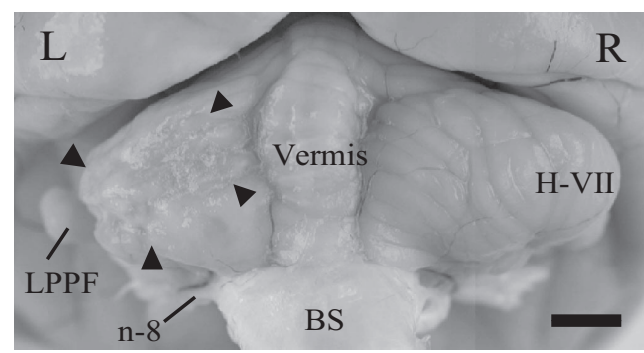

M1
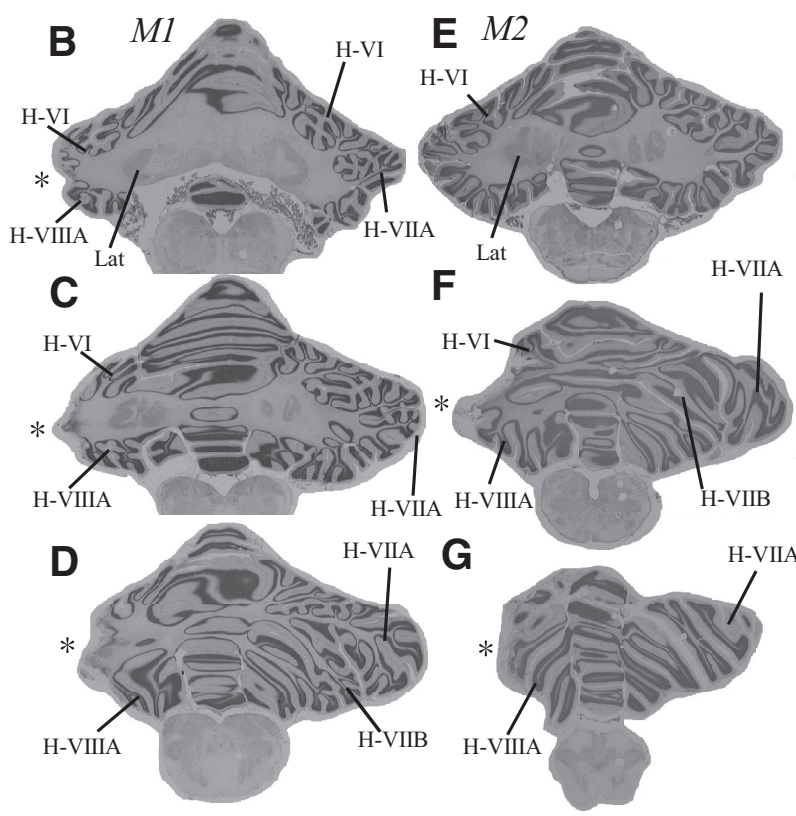

K
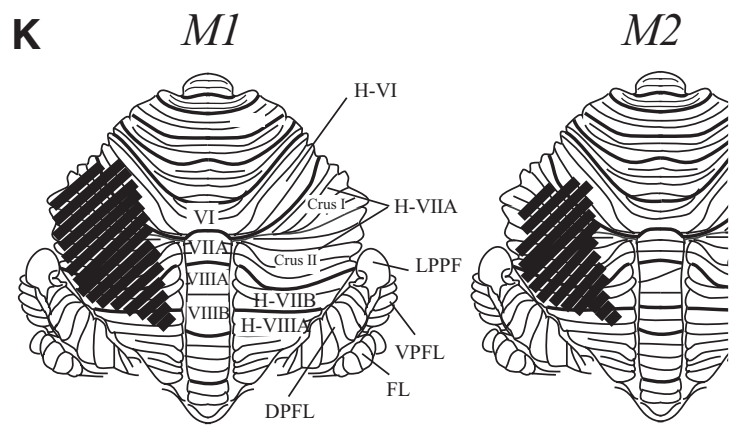
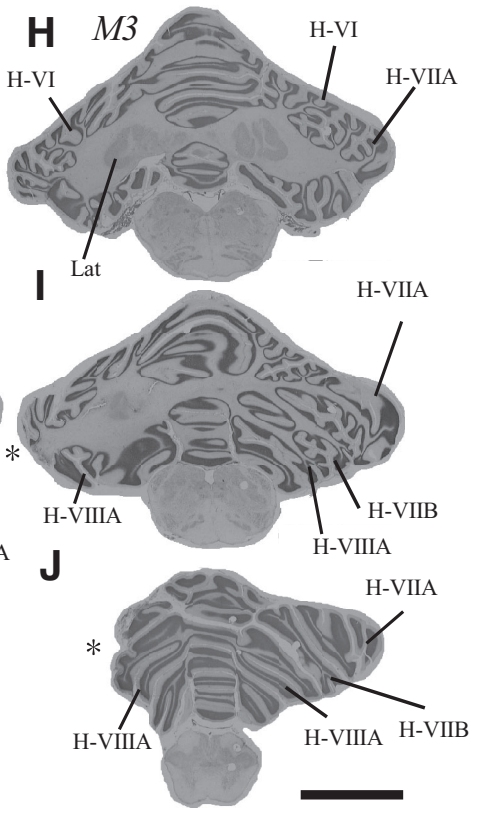

FIG. 2. Lesions of cerebellar hemispheric lobules in the 3 monkeys. A: caudal view of the extracted cerebellum of monkey M1. The area surrounded by $\boldsymbol{\Delta}$ in the left cerebellar hemisphere was lesioned. $B-D$ : coronal sections of the cerebellum of monkey $M 1$ at $5 \mathrm{~mm}$ $(B), 8 \mathrm{~mm}(C)$, and $10 \mathrm{~mm}(D)$ posterior to the VIIIth nerve. $E-G$ and $H-J$ : coronal sections of monkeys $M 2(E-G)$ and $M 3(H-J)$ shown similarly to $B-D$. *, in $B-J$, lesioned hemispheres. $K$ : extents of hemispheric lesions in the 3 monkeys. Areas covered by oblique lines on the schemata of the unfolded monkey cerebellum (Larsell and Jansen 1970) indicate lesioned hemisphere. Scale bars, $5 \mathrm{~mm}(A)$ and $10 \mathrm{~mm}(B-J)$. BS, brain stem. DPFL, dorsal paraflocculus. FL, flocculus. H-VI, hemispheric lobule VI. H-VIIA, hemispheric lobule VIIA. H-VIIB, hemispheric lobule VIIB. HVIIIA, hemispheric lobule VIIIA. n-8, VIIIth nerve. L, left side. Lat, dentate nucleus. LPPF, lobulus petrosus paraflocculus. $\mathrm{R}$, right side. VI, vermal lobule VI. VIIA, vermal lobule VIIA. VIIIA, vermal lobule VIIIIA. VIIIB, vermal lobule VIIIB. VPFL, ventral paraflooculus.

\section{Effects on smooth pursuit eye movements}

To the step $\left(3^{\circ}\right)$-ramp $\left(5-20^{\circ} / \mathrm{s}\right)$ target motion, the monkeys showed initial brief accelerating pursuit eye movements usually 80-140 ms after the onset of target motion until the catch-up saccade occurred before lesioning (Figs. 3 and 4). After hemispheric lesioning, the initial pursuit was depressed in all directions in monkey $M 1$, as shown in Fig. $3, E-H$. In particular, the initial pursuit in the ipsiversive (leftward) direction was so much depressed that it could not be clearly differentiated from the following catch-up saccades (Fig. 3E). However, the onset of initial pursuit in the contraversive (rightward) and downward directions, estimated by the flexion points on the averaged eye position traces in Fig. 3, $F$ and $G$, was delayed only a little. The initial pursuit was also depressed in monkey M3 in the ipsiversive, contraversive and downward

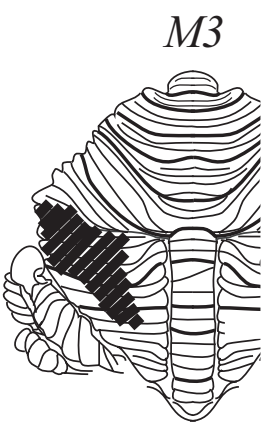

directions (Fig. 3, $I-K$ ). The onset of initial pursuit in the ipsiversive direction, which had been exceptionally early (ca. $20 \mathrm{~ms}$ after the onset of target motion) before lesioning, was delayed to ca. $90 \mathrm{~ms}$ after lesioning (Fig. 3I), whereas those in the contraversive and downward directions were not much delayed (Fig. 3, $J$ and $K$ ). In monkey $M 2$, the durations of the initial pursuit were generally short $(<40 \mathrm{~ms})$, so that changes related to lesioning were not clearly seen (not shown in figures).

Postsaccadic pursuit eye movements were depressed by hemispheric lesioning (Figs. 3 and 4). We quantified the postsaccadic pursuit velocities at $60-110 \mathrm{~ms}$ after the midpoints of catch-up saccades because effects of secondary catch-up saccades, which were very frequently induced after hemispheric lesioning, were comparatively small in this 


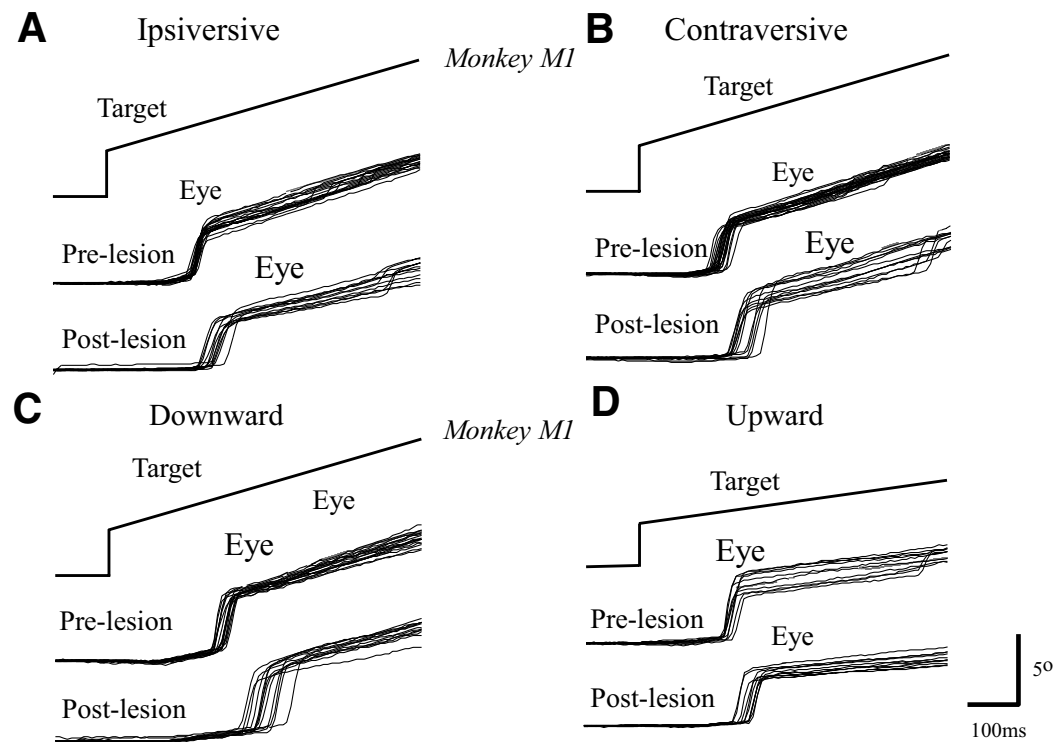

F Contraversive Monkey M1
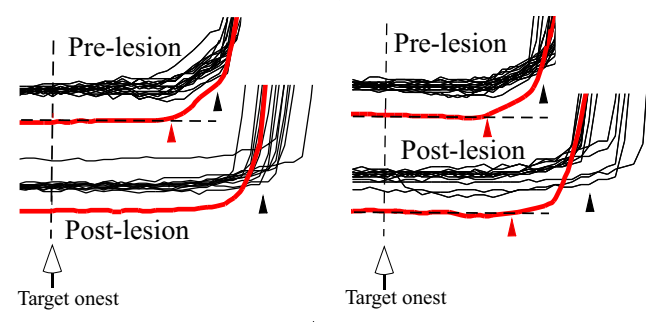

I Ipsiversive

$\mathbf{J}$

Contraversive

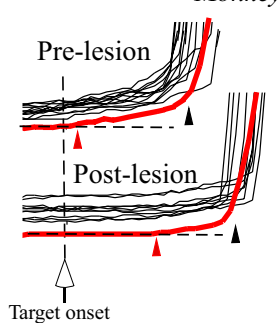

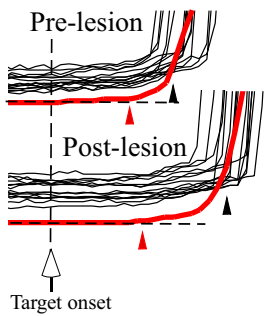

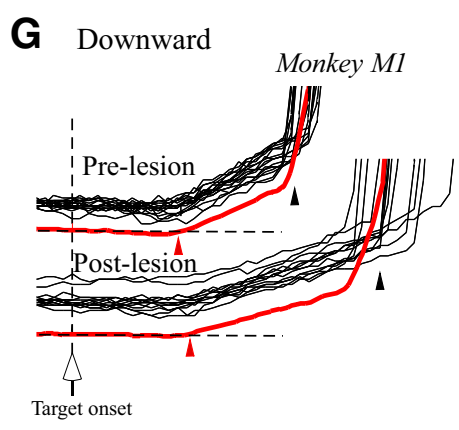

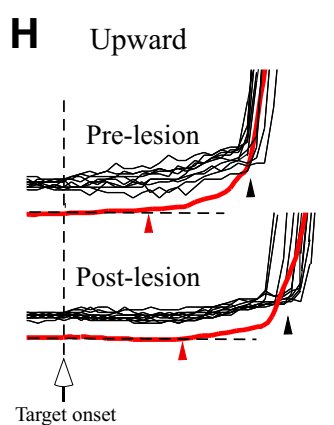

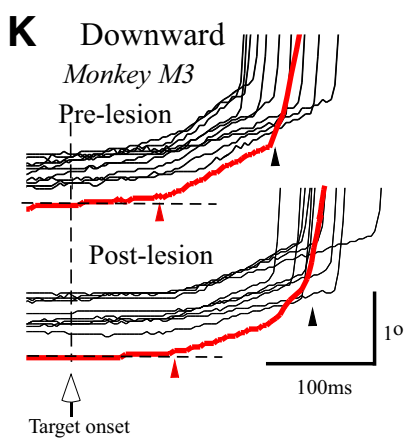

FIG. 3. Examples of eye position traces aligned at the onset of target motion to step (3 )-ramp $\left(10^{\circ} / \mathrm{s}\right.$ in $A-C$ and $5 \%$ in $\left.D\right)$ target motion. $A-H$ : data for monkey M1. In $A$, target and eye position traces in the ipsiversive direction are aligned at the onsets of target jump before (prelesion) and $2 \mathrm{wk}$ postlesion. $B-D$ : target and eye position traces similar to $A$ but for contraversive $(B)$, downward $(C)$, and upward $(D)$ directions. In $E-H$, the initial smooth pursuit eye movements and the onsets of catch-up saccades before (prelesion) and at 2 wk postlesion (postlesion) in $A-D$ are shown, respectively. Red curves show the averaged eye position traces. $I-K$ : similar to $E-G$ but for data of monkey $M 3$ to step $\left(3^{\circ}\right)$-ramp $\left(10^{\circ} / \mathrm{s}\right)$ target motion. Red triangles show the onsets of initial pursuit estimated by the flexion points on the averaged eye position traces. In monkey $M 1$, the initial pursuit was not clearly differentiated from catch-up saccades after lesioning, so that its onset could not be estimated $(E)$. Black triangles indicate mean onset time for the catch-up saccades. Note that the onsets of catch-up saccades were delayed in both 2 monkeys. Scale bars, 100 $\mathrm{ms}$ and $5^{\circ}(A-D)$ or $1^{\circ}(E-K)$. time window. Before hemispheric lesioning, postsaccadic pursuit velocities were dependent on the target velocity in all the directions $(P<0.05$, Kruskall-Wallis ANOVA, Fig. $5)$. The velocity of the upward postsaccadic pursuit was low compared with those of the other directions in these three monkeys (Figs. $3 D$ and $4 D$ ). The average velocities were $5.9 \pm 0.1 \%$ s (mean $\pm \mathrm{SE}$ of 3 or 4 directions) for $5 \% \mathrm{~s} \mathrm{ramp}$ target velocity, $9.2 \pm 0.1 \% \mathrm{~s}$ for $10 \% \mathrm{~s}, 12.2 \pm 0.1 \%$ for $15 \%$, and $15.6 \pm 0.1 \%$ for $20 \%$ on the average for the three monkeys in the ipsiversive, contraversive, and downward directions. Thus the postsaccadic pursuit velocities measured shortly after the catch-up saccades were slightly hypermetric at $5 \% \mathrm{~s}$ ramp target velocity, and hypometric at target velocity $>10 \%$, in accordance with the previous report on monkeys (Hiramatsu et al. 2008; Nagao and Kitazawa 1998) and humans (Ogawa and Fujita 1997). As shown in Figs. $4 A$ and $5 A$, velocities of the postsaccadic pursuit in the ipsiversive direction decreased on average by $27 \%$ for $5-20 \%$ s ramp target velocities $(P<0.01$, ANOVA for repeated measurements) at 2 wk postlesion in monkey M1. A decrease in the velocities of the postsaccadic pursuit in the ipsiversive direction was also observed in monkeys $M 2$ and $M 3(P<0.01$, Fig. 5, $E$ and $I)$. These depressant effects on the postsaccadic pursuit velocity in the ipsiversive direction were observed at 4 wk postlesion in monkeys $M 1$ and M3 $(P<0.01)$ but recovered in monkey M2. The depressive effects on postsaccadic pursuit were large at relatively fast $(15-20 \%$ s) target velocities in monkeys $M 1$ and $M 3$ (Fig. 5, $A$ and $I$ ).

Hemispheric lesioning also affected velocities of the postsaccadic pursuit eye movements in the other directions. The velocity of contraversive pursuit decreased in all the three 
A

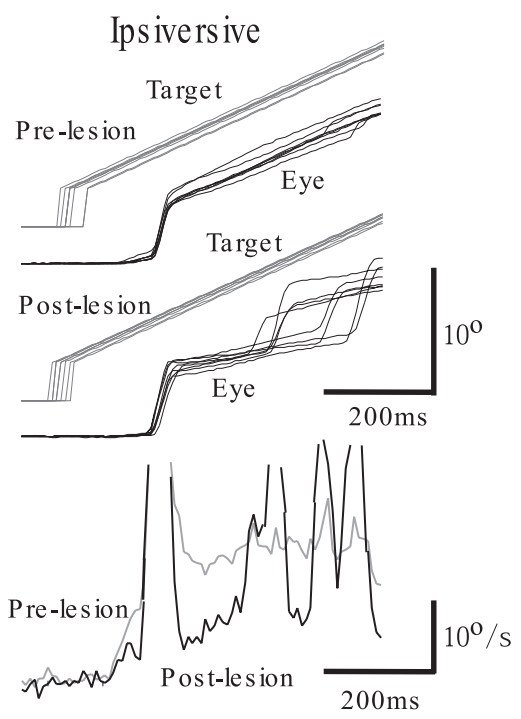

C
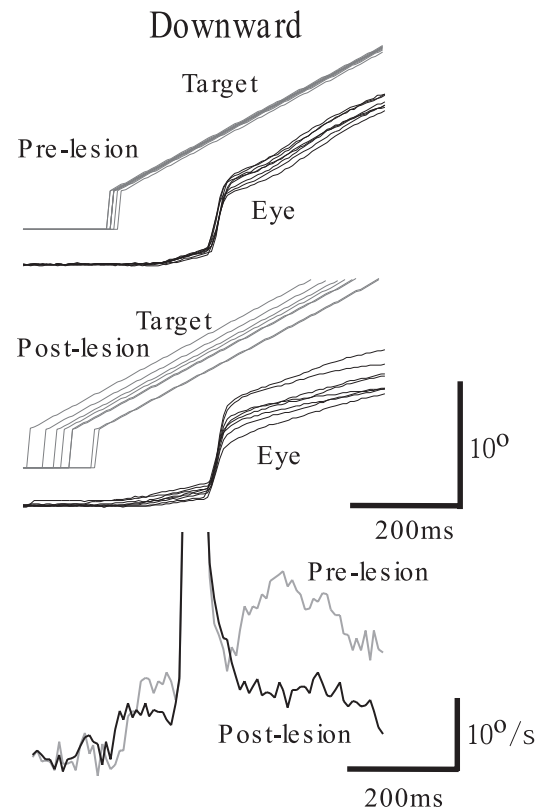

B

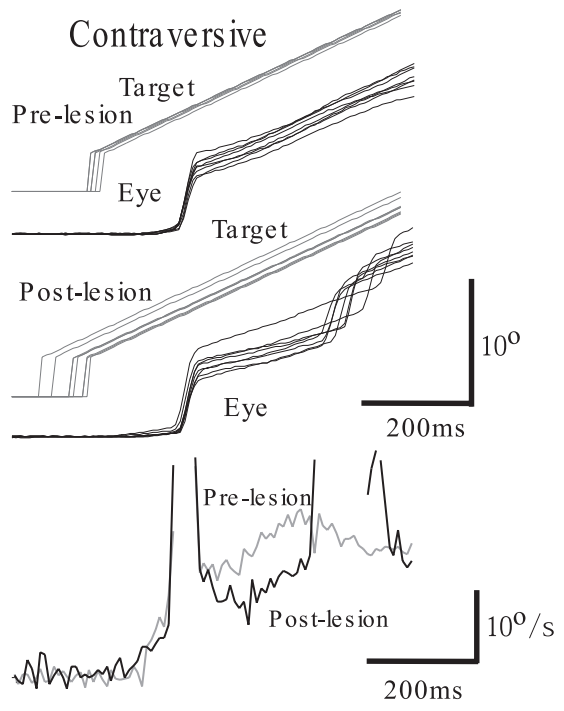

Upward
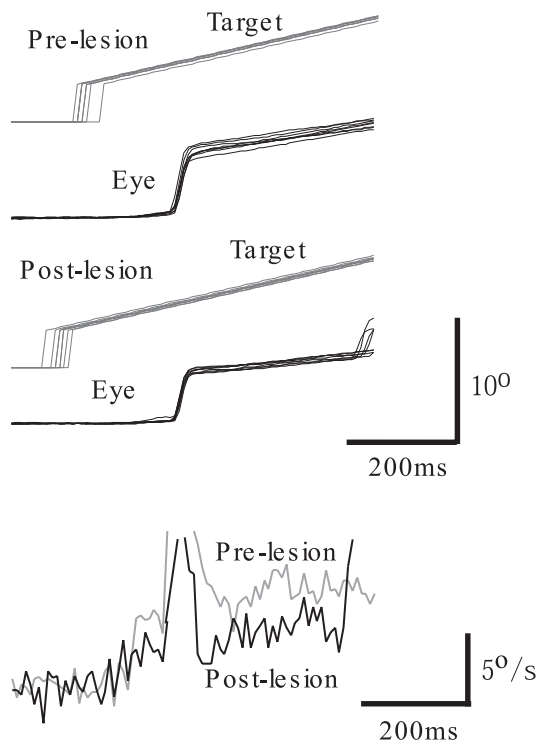

FIG. 4. Examples of eye movement traces to step-ramp moving target in monkey $M 1$. Step size was $3^{\circ}$, and ramp target velocities were $20 \%$ s $(A-C)$ or $10 \%$ s $(D)$. A : eye and target position traces and averaged eye velocity traces aligned at the midpoints of catch-up saccades in the ipsiversive direction before (prelesion, gray curve) and after (postlesion, black curve) cerebellar hemispheric lesioning. $B-D$ : target position, eye position and eye velocity traces similar to those in $A$ but for contraversive $(B)$, downward $(C)$, and upward $(D)$ directions. Scale bars, $200 \mathrm{~ms}$, and $10^{\circ}, 10^{\circ} \mathrm{s}$, or $5 \%$ s. monkeys at $2 \mathrm{wk}$ postlesion. The decrease of velocity was still detectable at 4 wk postlesion in monkeys $M 1$ and $M 2(P<$ 0.01 , Fig. $5, B, F$, and $J$ ). The velocity of downward pursuit decreased in monkeys $M 2(P<0.05)$ and $M 3(P<0.01)$, which recovered at 4 wk postlesion (Fig. 5, $G$ and $K$ ). The velocity of upward pursuit decreased in monkey $M 1$ at 2 and 4 wk postlesion $(P<0.01$, Fig. $5 D)$. To summarize, unilateral hemispheric lesioning markedly depressed the velocity of the postsaccadic pursuit in the ipsiversive direction and moderately affected those in the other directions.

\section{Effects on visually guided saccades}

In this study, we focused on eye movements induced by step-ramp away target motion, and measured visually guided saccades to a stationary target only for calibrating eye positions before starting the daily sessions. Figure 6 shows examples of $5^{\circ}$ visually guided saccades in the four directions before and after hemispheric lesioning. The mean amplitudes and latencies were $4.2-5.1^{\circ}$ and $155-184 \mathrm{~ms}$ in monkeys $M 1$ and M2 before lesioning (Fig. 6, $A-H$ ). Monkey MI often made postsaccadic drifts in horizontal directions or presaccadic drifts in vertical directions that may be due to overtraining to step-ramp moving target motions.

After unilateral hemispheric lesioning, visually guided saccades were impaired (Figs. 6 and 7). In monkey M1, the onsets were delayed in all directions by $12-46 \mathrm{~ms}(P<0.05$ for the ipsiversive direction, $P<0.01$ for the other 3 directions; Welsh $t$-test) at 2 wk postlesion (Figs. 6, $A-D$, and $7 A$ ). The amplitudes showed a tendency of increased trial-to-trial variability in four directions that was indicated by an increase in the coefficients of variation (SD/mean) of the amplitudes (0.032-0.074 at prelesion vs. 0.091-0.112 at 2 wk postlesion). However, no hypo- or hypermetria was recognized (Fig. 6, $A-D$ ). In monkey $M 2$, the onsets of saccades in the four directions were also delayed at $2 \mathrm{wk}$ 


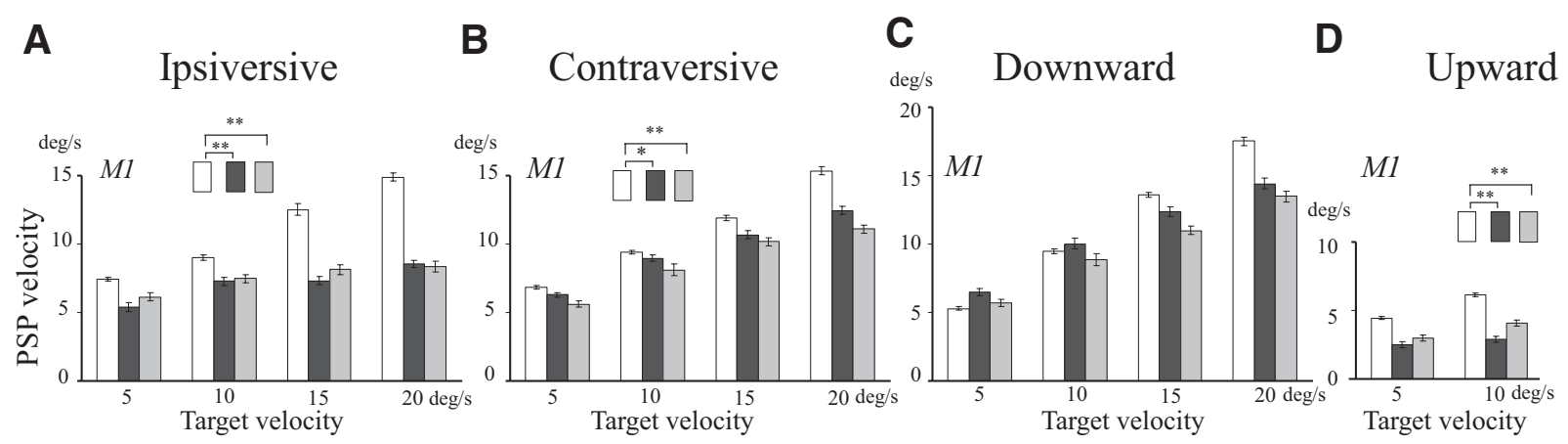

E

$\mathbf{F}$

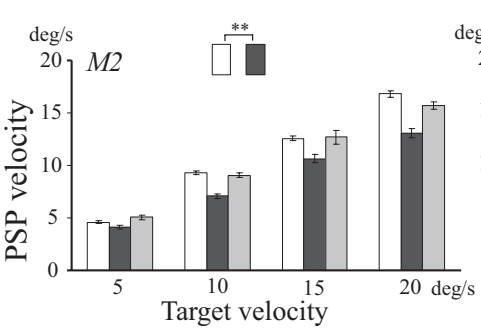

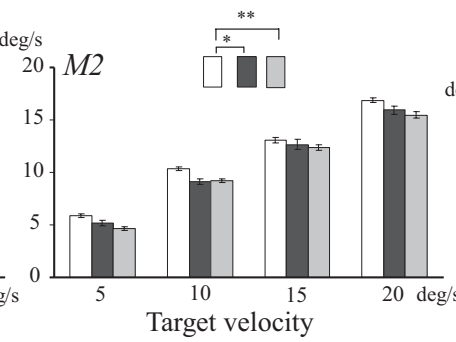

G

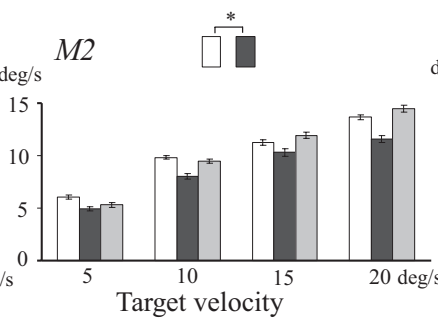

H
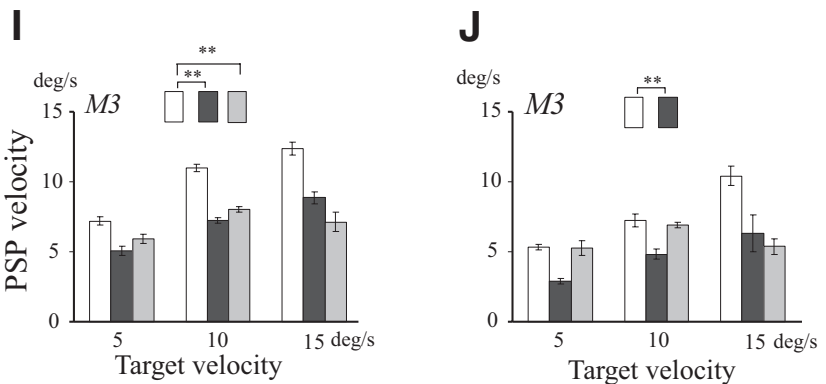

$\mathbf{K}$
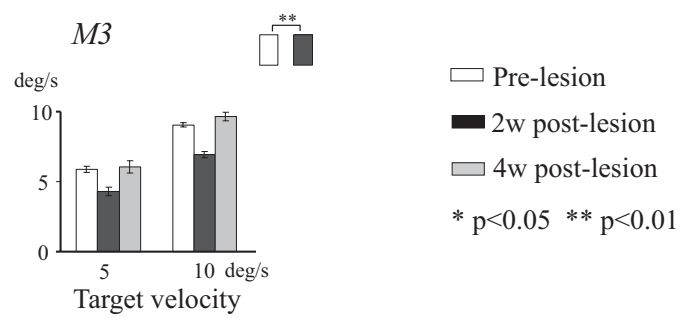

FIG. 5. Summary of changes in postsaccadic smooth pursuit (PSP) velocities after unilateral lesioning of cerebellar hemisphere. PSP velocities were examined using a step $\left(3^{\circ}\right)$-ramp $\left(5,10,15,20^{\circ}\right.$ s) moving target in the ipsiversive $(A)$, contraversive $(B)$, downward $(C)$, and upward $(D)$ directions. Mean eye velocities are compared before hemispheric lesioning ( $\square$ ), at $2 \mathrm{wk}(\square)$, and at $4 \mathrm{wk}(\square)$ postlesion. $A-D, E-H$, and $I-K$ are obtained from monkeys $M 1, M 2$, and $M 3$, respectively. Bars indicate SE. **, $P<0.01$; $^{*}, P<0.05$ (ANOVA for repeated measurements).

postlesion $(P<0.01$ for the ipsiversive, downward and upward directions, $P<0.05$ for the contraversive direction, Figs. 6, $E-H$, and $7 B$ ). The amplitudes showed a slight tendency of increased trial-to-trial variability in the ipsiversive and downward directions (coefficients of variation of amplitudes, 0.063-0.064 at prelesion vs. $0.068-0.084$ at 2 wk postlesion), but no hypo- or hypermetria was recognized except for the upward direction in which the amplitudes decreased from $5.1 \pm 0.1$ to $4.6 \pm 0.1^{\circ}(P<0.05$, Fig. $6 H)$. The mean amplitudes and latencies of monkey $M 3$ were $4.6-4.9^{\circ}$ and $126-160 \mathrm{~ms}$, which are nearly within the range of express saccades, before lesioning. The onsets were delayed by $35-55 \mathrm{~ms}$ in the three directions $(P<0.01)$ at 2 wk postlesion (Fig. 7C), but the amplitudes were not hypoor hypermetric except for a slight increase in the trial-totrial variability in the ipsiversive direction (not shown in figures). Some recovery was recognized in the delays of the onsets of visually guided saccades at $4 \mathrm{wk}$ postlesion in these three monkeys (Fig. 7, $A-C$ ). Thus lesions of unilateral hemisphere delayed the onset of $5^{\circ}$ visually guided saccades and decreased precision in their amplitudes. As the eye fixation on the central target before target jump was not so much impaired after lesioning (Fig. 6, $A-H$ ), the possibility that the decrease in saccade amplitude precision might be induced by the less rigid eye position control was very small.

\section{Effects on catch-up saccades}

To step $\left(3^{\circ}\right)$-ramp $\left(5-20^{\circ} / \mathrm{s}\right)$ target movements, the three monkeys responded with $3-5^{\circ}$ catch-up saccades at the latencies of 140-260 ms (Fig. 3), which were not dependent on the target velocities or directions except for the downward direction in monkey $M 1$ (Figs. $3 C$ and $7 D$ ). The amplitudes of the catch-up saccades were slightly dependent on the ramp target velocities in these three monkeys: $3.5 \pm 0.2^{\circ}$ for $5 \% \mathrm{~s}, 4.2 \pm$ $0.2^{\circ}$ for $10^{\circ} \mathrm{s}, 4.8 \pm 0.4^{\circ}$ for $15^{\circ} \mathrm{s}$, and $5.7 \pm 0.4^{\circ}$ for $15 \%$ s on the average in the ipsiversive, contraversive, and downward directions.

After unilateral hemispheric lesioning, onsets of catch-up saccades were delayed in all directions (Fig. 3). As summarized in Fig. $7 D$, the onsets of catch-up saccades were delayed by $16-50$ $\mathrm{ms}$ in monkey $M 1(P<0.01)$ in all the directions at $2 \mathrm{wk}$ postlesion. Delays were still present at $4 \mathrm{wk}$ postlesion in the ipsiversive $(P<0.05)$, contraversive $(P<0.05)$, and upward $(P<0.05)$ directions. In monkey $M 2$, the onsets of catch-up saccades were delayed in the ipsiversive $(P<0.05)$, downward 
A Ipsiversive

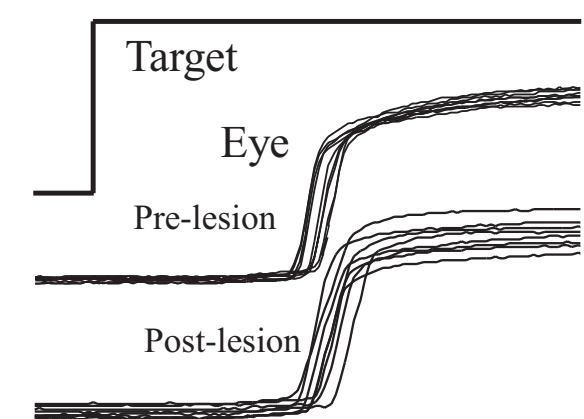

C

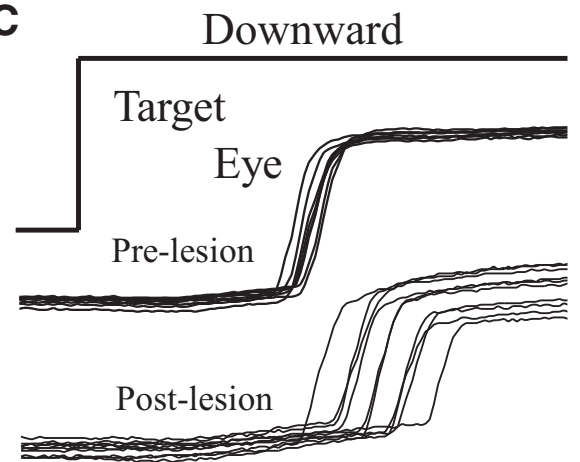

E

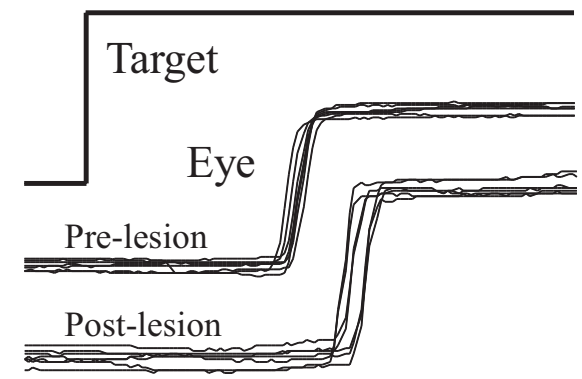

G

Downward

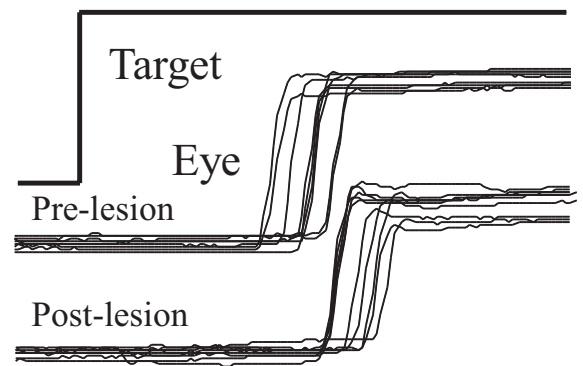

B
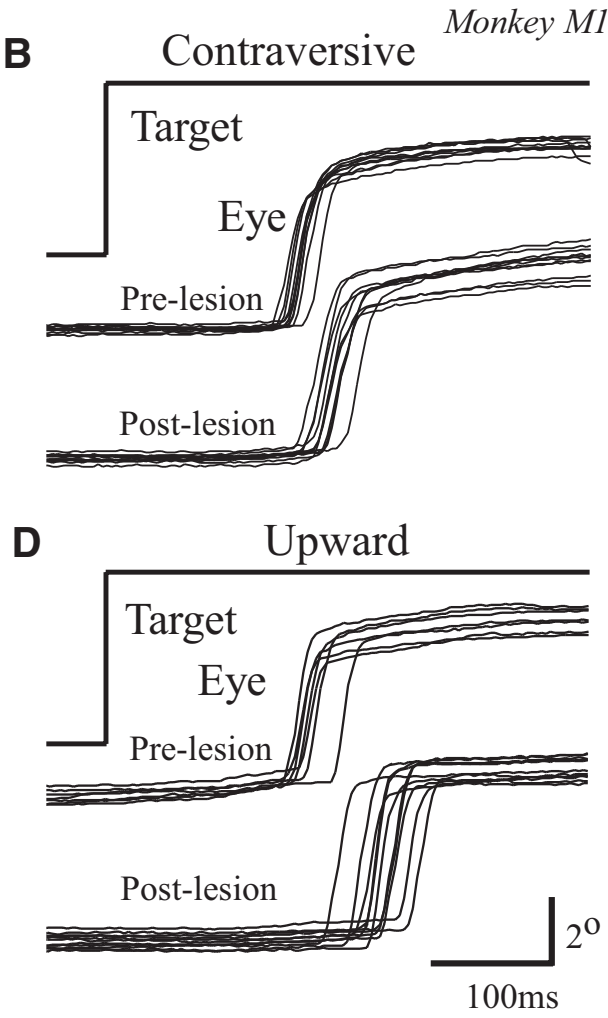

$\mathbf{F}$
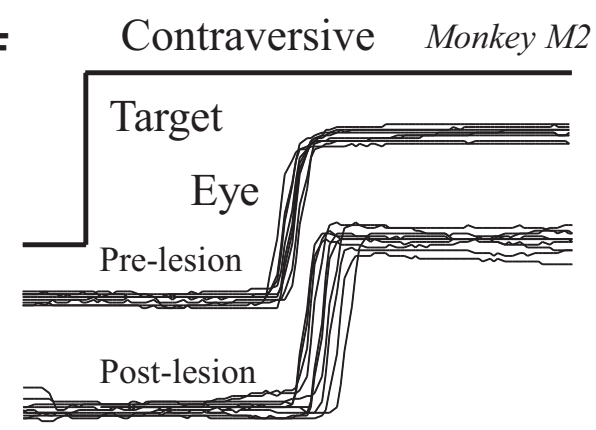

H

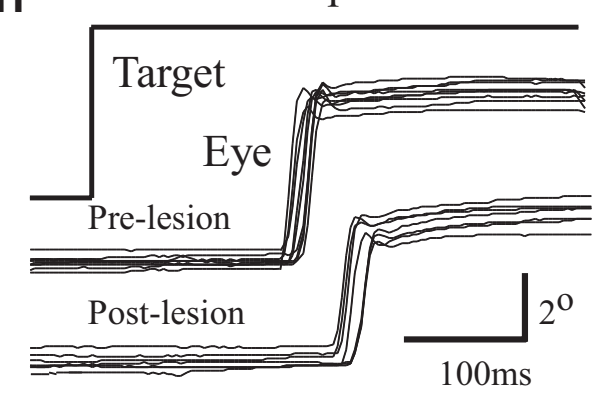

FIG. 6. Examples of visually guided saccades to the stationary target presented $5^{\circ}$ from the central fixation point. $A-D$ : target (Target) and eye (Eye) position traces of prelesion and $2 \mathrm{wk}$ postlesion in the ipsiversive $(A)$, contraversive $(B)$, downward $(C)$, and upward $(D)$ directions for monkey $M 1$. Eye position traces are aligned at the onsets of target jump. $E-H$ : similar to $A-D$ but data for monkey M2. Scale bars, $100 \mathrm{~ms}$ and $2^{\circ}$.
$(P<0.01)$, and upward $(P<0.01)$ directions by $10-44 \mathrm{~ms}$ at 2 wk postlesion. Delays were still present at 4 wk postlesion for the ipsiversive $(P<0.05)$ and downward $(P<0.01)$ directions (Fig. 7E). In monkey M3, the onsets of catch-up saccades in the ipsiversive $(P<0.01)$, contraversive $(P<0.05)$ and downward $(P<0.01)$ directions were delayed by $14-73 \mathrm{~ms}$ at $2 \mathrm{wk}$ postlesion. Again, these delays were still observable at $4 \mathrm{wk}$ postlesion for the downward $(P<0.01)$ direction (Fig. $7 F)$. These delays in the onsets of catch-up saccades may not be the secondary effects induced by the depressed initial pursuit eye movements, because onsets of the $5^{\circ}$ visually guided saccades to the stationary target were also delayed after hemispheric lesioning. The effects of hemispheric lesioning on the amplitudes of catch-up saccades were mild, as shown in Figs. 3 and 4 (also, see Fig. 8). The amplitudes of catch-up saccades increased by $7.8 \%$ on the average in the four directions for monkey $M 1$ but did not increase or decrease in the other two monkeys. Thus lesions of unilateral hemisphere delayed the onsets of both the visually guided and 


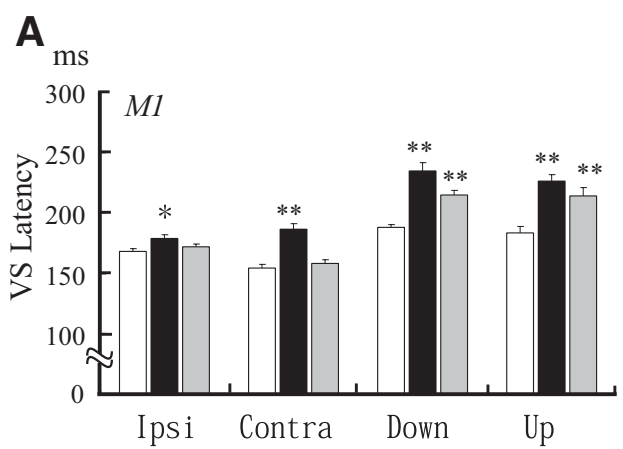

D
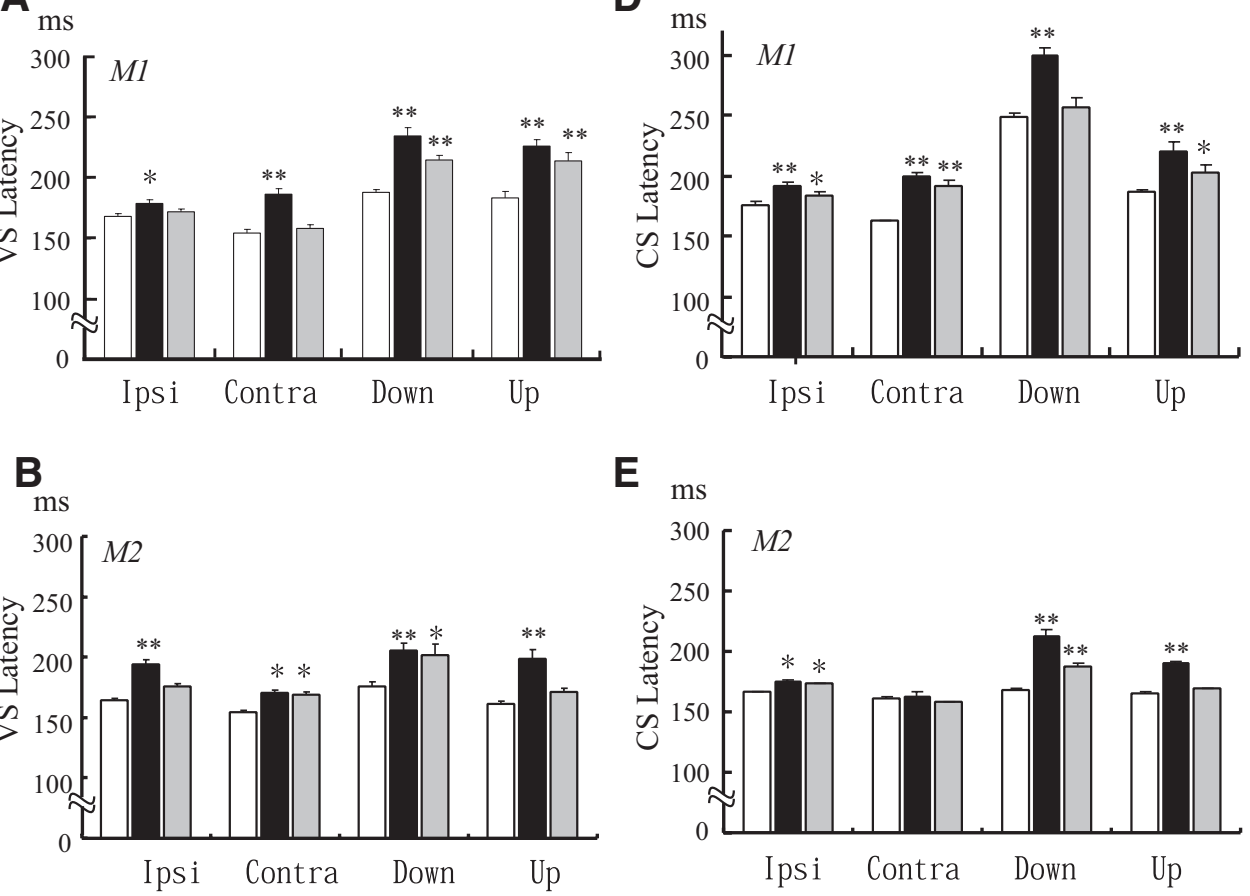

E
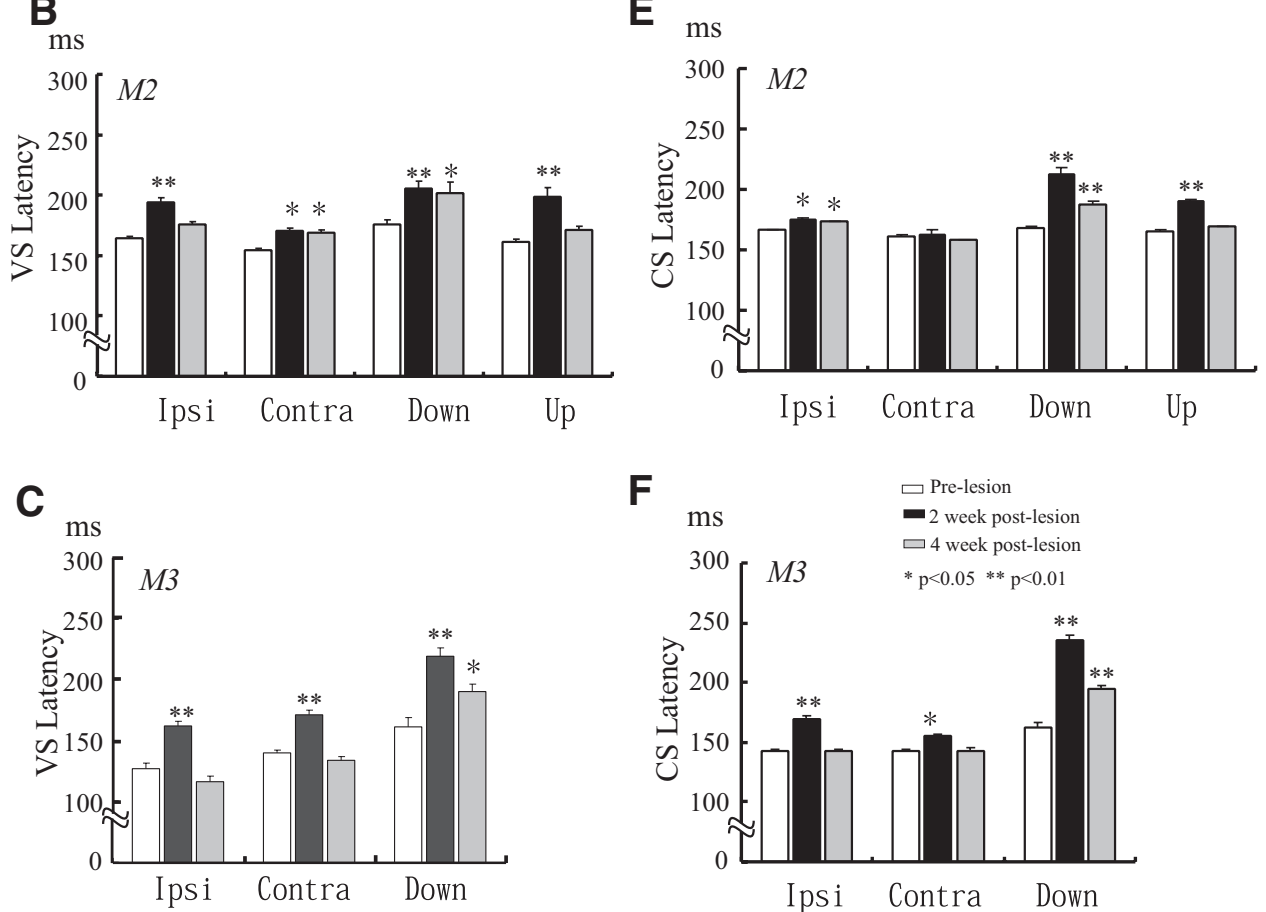

$\mathbf{F}$

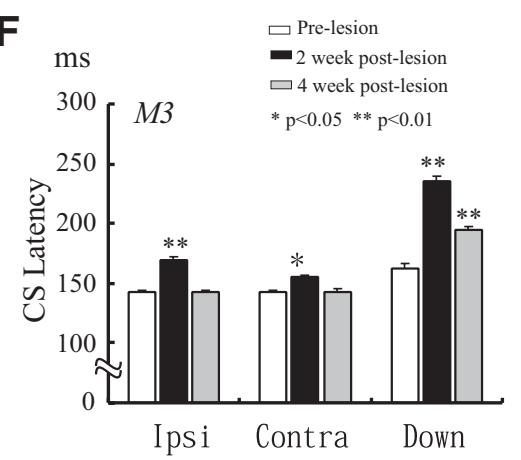

FIG. 7. Summary of changes in the latencies of visually guided (VS) and catch-up (CS) saccades after unilateral lesioning of cerebellar hemisphere. The latencies of onsets of $5^{\circ}$ visually guided saccades $(A-C)$, and those of catch-up saccades to the step $\left(3^{\circ}\right)$-ramp $\left(5-20^{\circ} / \mathrm{s}\right)$ target motion $(D-F)$ are averaged for ipsiversive (Ipsi), contraversive (Contra), downward (Down), and upward (Up) directions. $\square, \mathbf{\square}$, and $\square$, data for prelesion, $2 \mathrm{wk}$, and 4 wk postlesion, respectively. $A$ and $D$ : data for monkey M1. B and $E$ : data for monkey $M 2$. $C$ and $F$ : data for monkey M3. Data were obtained from 15 to 30 trials. Bars indicate SE. *, $P<0.05$; **, $P<0.01$ by Welsch $t$-test. catch-up saccades in the four directions and decreased precision in the amplitudes of visually guided saccades.

\section{Effects on adaptations of postsaccadic smooth pursuit velocity}

The adaptation of postsaccadic smooth pursuit velocity was tested by presenting repeated accelerations of target ramp velocity from 10 to $20 \%$ s for $250 \mathrm{~ms}$ at the midpoint of catch-up saccades in the ipsiversive, contraversive, and downward directions, respectively. We did not test adaptation in the upward direction because pursuit velocity in upward direction was generally slow compared with those in the other directions (Fig. 5). Before the hemispheric lesioning, all the three monkeys showed an adaptive increase in postsaccadic smooth pursuit velocity by $25-60 \%$ after $100-160$ adaptation trials (Figs. 8 and 9). At the beginning of the adaptation trials, the monkeys could not follow the target well and often showed secondary catch-up saccades (e.g., Fig. 8, $B$ and $F$ ). However, after 96-128 adaptation trials, the postsaccadic smooth pursuit velocity at $0-100 \mathrm{~ms}$ after the target acceleration gradually increased, implying that the monkeys could accelerate smooth pursuit without using actual perceived target motion signals by learning (Fig. 8, $C$ and $D$ and $G$ and $H$ ). The postsaccadic smooth pursuit velocity increased by $50-60 \%$ on average in the 10th block (after 160 adaptation trials, Fig. 9, J-L) in all of the three directions. We tested the adaptation of postsaccadic pursuit velocity in the three monkeys at 1-4 wk postlesion, twice for each direction. Hemispheric lesioning depressed adaptation of postsaccadic smooth pursuit velocities. In monkey $M 1$, the postsaccadic smooth pursuit velocity in the ipsiversive direction did not adaptively increase at 2 and $4 \mathrm{wk}$ postlesion (see Fig. 8, $K$ and $L$ ). In monkeys $M 2$ and $M 3$, in which the depressant effects of hemispheric lesioning on the postsaccadic smooth pursuit velocity were relatively mild (Fig. 5 ), the adaptation of postsaccadic smooth pursuit velocity in the ipsiversive direction was also impaired at 2 and 4 wk postlesion (Fig. 8, $O$ and $P$, also see Fig. 9, $D$ and $G$ ). In monkey $M 2$, the pursuit velocity increased gradually $150 \mathrm{~ms}$ after target acceleration during adaptation trials (Fig. 8P), implying that monkey M2 could accelerate the smooth pursuit velocity using perceived target motion signals. The early component of smooth pursuit might be preferentially impaired after hemispheric lesion in monkey M2. Because we examined adaptations only twice after lesioning for each monkey, we could not evaluate the lesion effects statisti- 

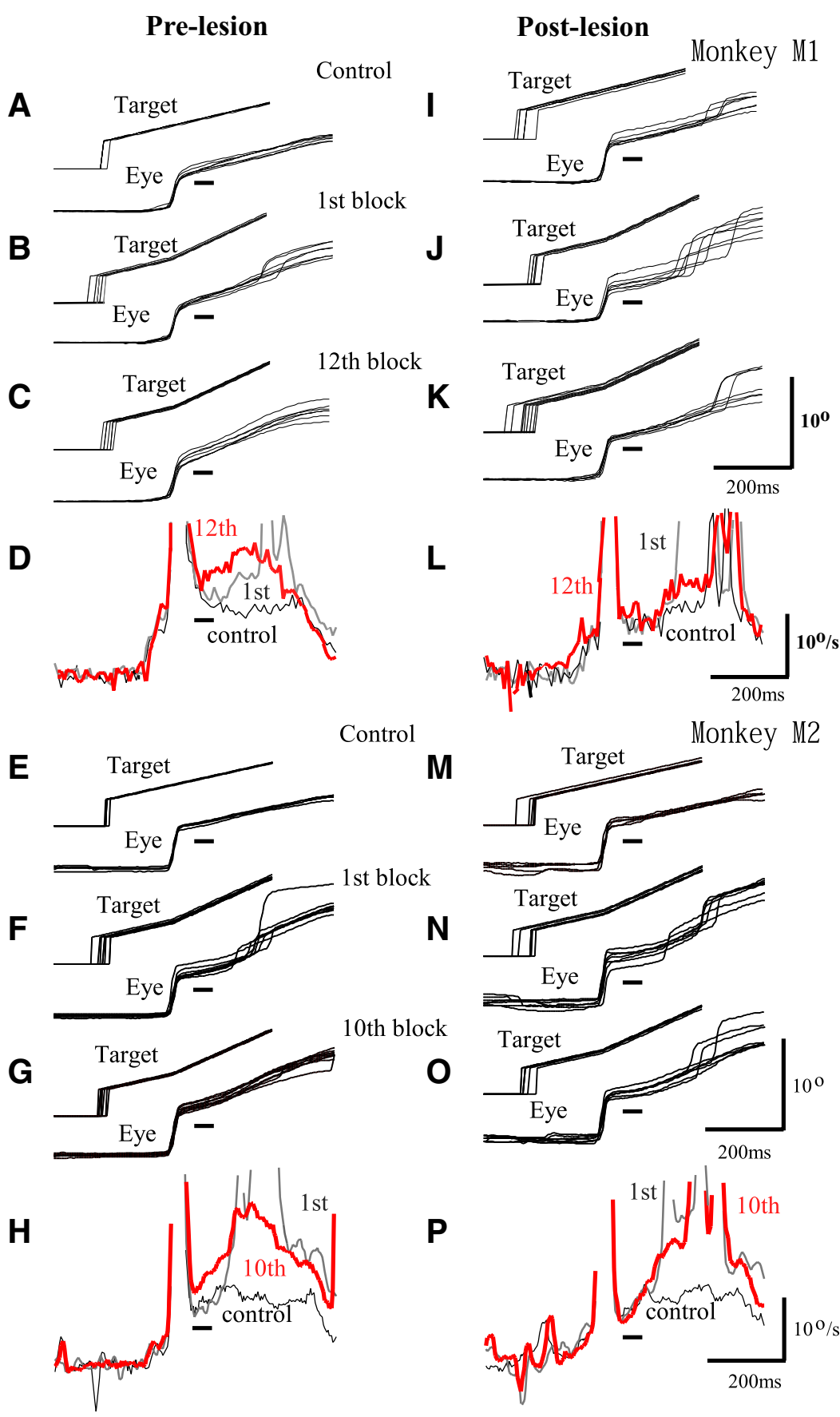

Control

\section{M}

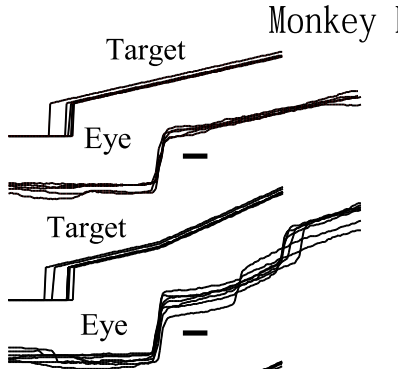

10th block

\section{st block}

$\mathbf{N}$

o

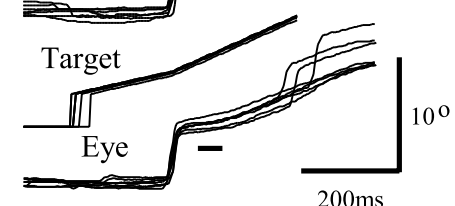

$\mathbf{P}$

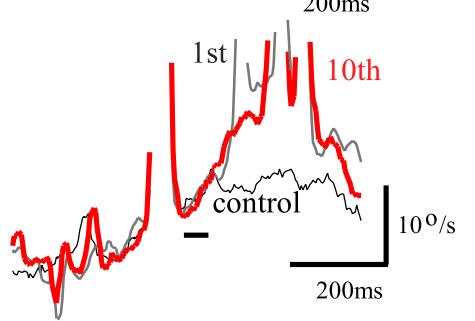

FIG. 8. Adaptation of postsaccadic smooth pursuit to step increase in target velocity at the midpoints of catch-up saccades. $A-D$ : data obtained before hemispheric lesioning in monkey M1. A: eye position and target traces during control trials. $B$ and $C$ : eye position and target traces at the 1 st (1st-16th trial) and 12th (177th-192th trial) blocks of adaptation trials. Note that in $B$, the monkeys could not follow the target sufficiently immediately after the target acceleration and often showed secondary catch-up saccades. $D$ : averaged eye velocities compared among control (black curve), 1st (gray curve), and 12th (red curve) adaptation blocks. $E-H$ : similar to $A-D$ but for data from monkey M2. G: eye position and target traces at the 10th (145th-160th trial) block of adaptation trials. $H$ : averaged eye velocities compared among control (black curve), 1st (gray curve), and 10th (red curve) adaptation blocks. $I-L$ : similar to $A-D$ but obtained at 2 wk postlesion from monkey $M 1$. $M-P$ : similar to $E-H$ but data obtained from monkey $M 2$ at 2 wk postlesion. Black bars attached to the eye position or velocity traces indicate the time when the mean postsaccadic smooth pursuit velocities (PSPVs) are calculated. Scale bars, $200 \mathrm{~ms}, 10^{\circ}$ or $20^{\circ} / \mathrm{s}$. cally for each monkey. Instead we evaluated the statistical significance of the lesion effects on the pooled data obtained from the three monkeys. Figure $9 J$ shows the averaged adaptation curves in the ipsiversive direction for the three monkeys before and after hemispheric lesioning. The adaptations of postsaccadic smooth pursuit velocity were depressed significantly at the group level $(P<0.01$, ANOVA for repeated measurements).

We also tested the adaptation of postsaccadic smooth pursuit velocity in the contraversive and downward directions. The adaptation of postsaccadic smooth pursuit velocities in the contraversive (Fig. 9, $B, E$, and $H$ ) and downward $(C, F$, and $I)$ directions were impaired at both 2 and $4 \mathrm{wk}$ postlesion in monkeys $M 1$ and M2 but not in monkey M3.
This may be a consequence of the smaller lesion size (Fig. $2 K$ ). Statistical significance was obtained in terms of depressant effects in the downward direction $(P<0.05$, Fig. $9 L)$ but not in the contraversive direction $(P>0.05$, Fig. $9 K)$ in the pooled data of these three monkeys. To summarize, lesions of hemisphere impaired the adaptation of postsaccadic smooth pursuit velocity in the ipsiversive and downward directions.

\section{I S C U S S I O N}

We used a brief (0.4-0.5 s) step-ramp target motion to examine smooth pursuit and saccadic eye movements. To step-ramp target motion, the monkey showed an initial slow 
A Ipsiversive
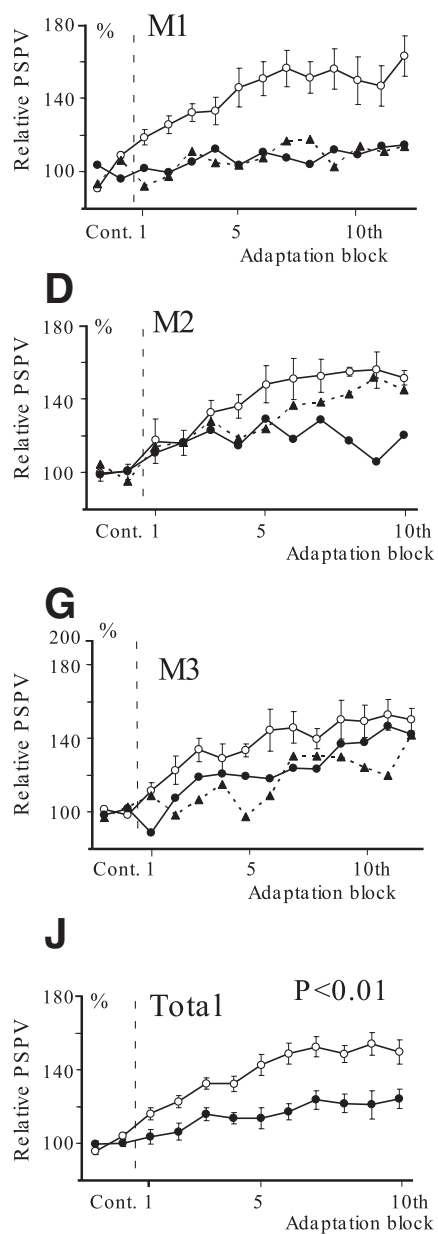

B Contraversive
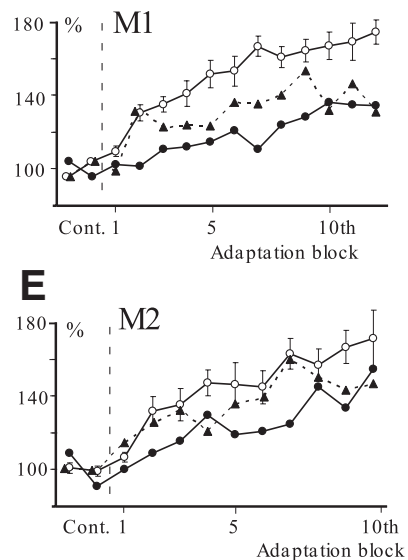

\section{$\mathrm{H}$}

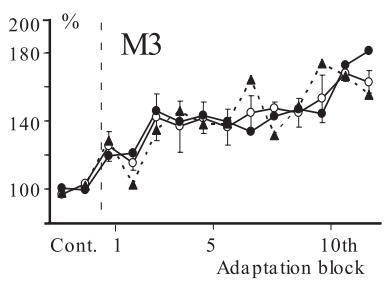

K

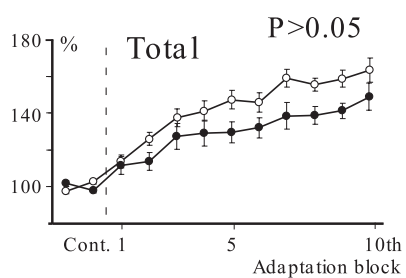

C Downward

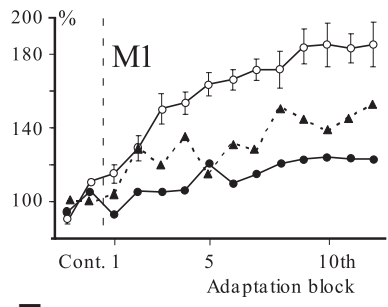

$\mathbf{F}$

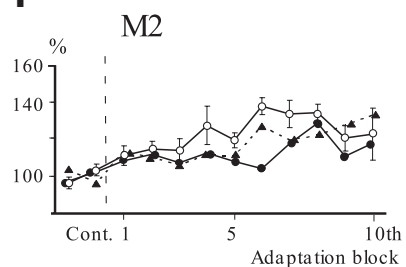

I

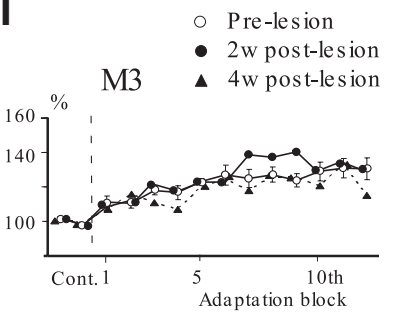

L

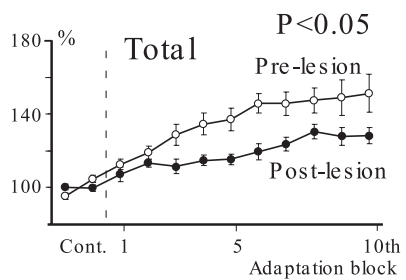

FIG. 9. Effects of cerebellar hemispheric lesion on the time course of adaptation of Postsaccadic pursuit velocity (PSPV). The control PSPV was obtained by averaging all the PSPVs in 2 control blocks (Cont). The mean PSPV in each block of adaptation trials (16 trials) was normalized to the control PSPV. $A-C$ : adaptation curves in the ipsiversive $(A)$, contraversive $(B)$, and downward $(C)$ directions for monkey $M 1$. $\bigcirc$, and $\boldsymbol{\Delta}$, data obtained before, at 2 and $4 \mathrm{wk}$ postlesion, respectively. $D-F$ : similar to $A-C$ but data for monkey $M 2$. $G-I$ : similar to $A-C$ but data for monkey M3. $J-L$ : averaged adaptation curves of these 3 monkeys in the ipsiversive $(J)$, contraversive $(K)$, and downward $(L)$ directions. Data for prelesion and postlesion are indicated by $\bigcirc$ and $\bullet$, respectively. $P<0.01$ by ANOVA for repeated measurements, $n=14$ (prelesion) and 6 (postlesion) in $J . P>0.05, n=15$ (prelesion) and 6 (postlesion) in $K . P<0.05, n=$ 13 (prelesion) and 6 (postlesion) in $L$. Bars indicate $\mathrm{SE}$. accelerating pursuit, later a small catch-up saccade and a postsaccadic smooth pursuit that roughly matched the target velocity. The latency of pursuit onset was usually $80-140 \mathrm{~ms}$ (also see Hiramatsu et al., 2008; Nagao and Kitazawa 1998). However, one monkey (M3) started its ipsiversive pursuit already $20 \mathrm{~ms}$ after the onsets of target motion (Fig. 3). This may be due to overtraining that may allow the monkey to predict target motion. The initial pursuit seems to be facilitated by training. The initial pursuit was not reported in Newsome et al. (1985) in which three different target motions (step, step-ramp away, and step-ramp toward motions) were randomly used for tests of smooth pursuit. We made unilateral lesions in the cerebellar hemispheric lobule VII (H-VII) and in a small portion of VI (H-VI) adjacent to the H-VII in three rhesus monkeys. The cerebellar nuclei were spared in all these monkeys. The initial pursuit eye movements in the ipsiversive, contraversive and downward directions were depressed in two monkeys, and their onsets were delayed in the ipsiversive direction in one monkey (Fig. 3). The postsaccadic smooth pursuit velocities in the ipsiversive and contraversive directions decreased at 2 wk postlesion (Figs. 4 and 5). They recovered in one monkey at 4 wk postlesion. The downward postsaccadic pursuit velocity also decreased at $2 \mathrm{wk}$ postlesion. It recovered in two monkeys at 4 wk postlesion. The upward postsaccadic smooth pursuit velocity decreased in one of the two monkeys. The depressive effects were recognized on smooth pursuit velocities $\leq 200 \mathrm{~ms}$ after the onsets of catch-up saccades (Fig. 3). The onsets of visually guided and catch-up saccades were delayed in all the directions at $2 \mathrm{wk}$ postlesion and partially recovered at $4 \mathrm{wk}$ postlesion. The amplitudes of visually guided saccades showed a tendency of increased trial-to-trial variability but did not show any hypo- or hypermetria (Figs. 6 and 7). The adaptation of postsaccadic smooth pursuit velocity, which was induced by repeated presentations of a brief acceleration of the target, was impaired in the ipsiversive and downward direction (Figs. 8 and 9). The depressant effects on smooth pursuit and saccade eye movements were most prominent in monkey $M 1$ in which the extent of the lesion was largest (Fig. 2), but the recovery and lesion size did not seem to be correlated in the other two monkeys. There is a possibility that some of these depressant effects might be enhanced by the imbalance caused by unilateral lesions. The results of our studies suggest that the cerebellar hemisphere (H-VI/VII) may be involved in smooth pursuit velocity and saccade timing/precision control.

\section{Voluntary eye movement control by oculomotor cerebellum}

It is well known that the monkey paraflocculus-flocculus complex and vermis are involved in voluntary eye movement 
control. Bilateral lesions of the flocculi and ventral paraflocculi decreased the gain of smooth pursuit (Rambold et al. 2002; Zee et al. 1981). Unilateral lesions of the lobulus petrosus paraflocculus decreased postsaccadic smooth pursuit velocity (Hiramatsu et al. 2008). Simple spikes in the flocculusparaflocculus complex are modulated by smooth pursuit or ocular following eye movements (Lisberger and Fuchs 1978; Miles et al. 1981; Nagao 1992; Noda and Mikami 1986; Shidara and Kawano 1993; Stone and Lisberger 1990). Bilateral lesions of vermal lobules VI/VIIA induced saccade hypometria, slightly delayed saccade onsets (Takagi et al. 1998; Barash et al. 1999), and decreased smooth pursuit velocity (Takagi et al. 2000). Simple spike activity in the vermal lobulus VI/VIIA are modulated by saccade (Catz et al. 2005; Kase et al. 1980; Ohtsuka and Noda 1995; Sato and Noda 1992; Thier et al. 2000) and smooth pursuit eye movements (Suzuki and Keller 1988a,b; Suzuki et al. 1981). Microstimulation within the vermal lobule VI/VIIA induced quick eye movements (Fujikado and Noda 1987; Noda and Fujikado 1987; Yamada and Noda 1987). Results of the present lesion study may add the cerebellar hemisphere (H-VI/VII) as a new member of the oculomotor cerebellum.

\section{Cerebellar hemisphere and smooth pursuit control}

The anatomical connections of H-VI/VII with neural circuitry for smooth pursuit are rather different from those of paraflocculus and vermis. The H-VII receives input from the FEF via the dorsolateral (DLPN) and dorsomedial (DMPN) pontine nuclei, and the nucleus reticularis tegmementi pontis (NRTP) (Xiong et al. 2002). Meanwhile the lobulus petrosus paraflocculus and the dorsal and ventral paraflocculi receive inputs from the middle temporal (MT) and medial superior temporal (MST) areas via the DLPN and NRTP (Glickstein et al. 1994; Nagao et al. 1997; Xiong and Nagao 2002). On the other hand, the vermal lobule VI/VIIA receives input from the DLPN, which are connected with FEF and MT/MST (Thielert and Thier 1993). Lesions or inactivation of the DLPN or NRTP depressed the velocity of smooth pursuit (May et al. 1988; Suzuki et al. 1999), and neurons in the DLPN, DMPN, and NRTP showed responses related to smooth pursuit (Dicke et al. 2004; Mustari et al. 1988; Ono et al. 2004; Suzuki and Keller 1984; Suzuki et al. 2003; Thier et al. 1988). These observations suggest that the FEF-cerebellar hemisphere pathway may constitute one distinct cerebro-cerebellar loop for the control of smooth pursuit. The H-VII issues its output to the parvocellular regions within the dentate and posterior interpositus nuclei (Xiong et al. 2002). Electrical stimulation of specific small portions of the dentate evoked slow oblique or vertical eye movements in monkeys (Chubb and Fuchs 1982; Ron and Robinson 1973). In our preliminary microstimulation study, we observed long-latency stimulation-induced slow or quick eye movements in oblique directions in H-VI/VII (Kitazawa et al. 2005). A unit recording study reported that most of monkey dentate neurons showed responses to vertical or oblique smooth pursuit, and only a small number of them showed responses to horizontal smooth pursuit (Chubb and Fuchs 1982). However, unilateral lesions of H-VI/VII depressed both the horizontal and vertical smooth pursuit (Fig. 5). Hence whether the H-VI/VII- parvocellular dentate/interpositus system is preferentially involved in the vertical or horizontal smooth pursuit remains open. There is a possibility that the FEF-hemisphere pathway may provide feedback to FEF as a transneural tracing anatomical study suggested that the monkey dentate nucleus issues outputs to the FEF via the thalamic ventral lateral nuclei (Lynch et al. 1994). However, we do not at present know whether the dentate neurons that receive direct input from the H-VI/VII actually send their output to FEF.

The present study revealed that unilateral lesions of $\mathrm{H}-\mathrm{VI} /$ VII depressed the adaptation of smooth pursuit velocity. Takagi et al. (2000) reported that lesions of the bilateral vermal lobule VI/VIIA depressed the adaptation of smooth pursuit velocity by half. Optican et al. (1986) reported that bilateral lesions of the flocculus and ventral paraflocculus depressed the adaptation of the ocular following eye movements. H-VII (Nagao et al. 2003), vermal lobule VI/VIIA (cat, Kyuhou and Matsuzaki 1991; monkey, Nagao et al. 2003), and ventral paraflocculus and flocculus (e.g., Nagao et al. 1997) receive climbing fibers from the caudal part of medial accessory olive (MAO), which is the source of retinal slip signals that are necessary for adaptation of ocular reflex (e.g., Ito 1984; Maekawa and Simpson 1973). The caudal MAO may also play a role in the adaptation of smooth pursuit velocity. One important feature of the adaptation of smooth pursuit velocity is that learning occurred rather rapidly. The postsaccadic pursuit velocity in this study increased by $20 \%$ within only 16 trials and by $50 \%$ after 100-20 trials (Fig. 9). This is in contrast to the adaptation of saccades (e.g., Robinson et al. 2006) or ocular reflexes (e.g., Shutoh et al. 2006), which require $>500$ trials to induce significant learning. One possible explanation for that discrepancy is that the parallel availability of cerebellar pathways for smooth pursuit control may speed up learning. Another possibility is that the monkeys might acquire a prediction strategy for the target acceleration during 100 trials.

\section{Cerebellar hemisphere and saccade control}

Lesions of unilateral H-VI/VI delayed the onsets of both the visually guided and catch-up saccades in all directions by 10-60 ms (Fig. 7). These delays might be explained by the reduced motivation to saccade tasks after brain surgery. However, given that simple spike activities in the hemisphere transiently increased or decreased around the onsets of saccades (Mano et al. 1991; Marple-Horvat and Stein 1990), we would relate these delays to the loss of Purkinje cells in this area. Lesions of H-VI/VII also affected the onsets of smooth pursuit, but their effects were rather different: the onsets of the ipsiversive pursuit were exceptionally early before lesionings in one monkey (M3) and returned to normal range after H-VI/VII lesions, while the onsets of initial pursuit for other directions were not changed in either of two monkeys (Fig. 3). Moreover, the latency of visually guided saccades in the ipsiversive direction in monkey M3 was slightly short for the ordinal saccades and returned to normal range after $\mathrm{H}-\mathrm{VI} / \mathrm{VII}$ lesions. One possible interpretation is that the training-induced prediction-based eye movements might be dependent on the cerebellar hemisphere. Several laboratories suggested that the cerebellar hemisphere is involved in timing control. Ohyama and Mauk (2001) suggested that the rabbit H-VI may play a role in timing control of eye blink reflex. Human imaging studies suggest that hemispheric lobule IV-VI (Kawashima et 
al. 2000) and posterior hemisphere (Dreher and Grafman 2002; Jueptner et al. 1995; Tracy et al. 2000) showed activity related to timing control of forelimb movements.

Unilateral H-VI/VII lesions induced no hypo- or hypermetria but showed a tendency of increased trial-to-trial variability in the amplitudes of visually guided saccades. A lack of hypometria is contrasting to those of vermal lesions: Takagi et al. (1998) reported amplitudes of saccades are decreased by $40 \%$, and also Barash et al. (1999) reported a severe hypometria. However, hypometria recovered completely after 3-12 mo, whereas a loss of adaptation of saccade amplitudes stayed $\leq 1$ yr after bilateral vermal lobule VI/VIIA lesions. Singleunit recording studies revealed that simple spike activity in the vermal lobule VI/VIIA are related to saccades (e.g., Ohtsuka and Noda 1995). Thier et al. (2000) reported that the amplitude and duration of saccades is encoded by the population responses of vermal simple spikes rather than by individual Purkinje cell activity. Complex spikes in the vermis were related to the adaptation of saccade amplitudes (Catz et al. 2005; Soetedj and Fuchs 2006). These observations suggest that the vermis may play a specific role in control of saccade amplitude or duration. Detailed single-unit studies will be needed to consider how the H-VI/VII is related to saccade control, and how its role is different from that of vermis.

The lateral part of the cerebellar hemisphere has been repeatedly suggested to be involved in not only motor control but also cognitive functions. Human imaging studies revealed that saccades in the presence of optokinetic stimulation, which require stronger visual-spatial attention than those in the absence of optokinetic stimulation (Dieterich et al. 2000), and the sequences of memory-guided saccades, which require visualspatial working memory (Heide et al. 2001; Nitschke et al. 2005), enhanced the activities of the hemisphere compared with those during simple visually guided saccades. Lindner et al. (2006) reported that the crus II in the hemisphere, as well as the frontal and parietal cortical areas, increased activities to the perceptual cancellation of smooth-pursuit-induced visual motion in human beings. These studies consistently indicated that the cerebellar hemisphere may play a role in the visual perception during voluntary eye movements. Thus a possibility is suggested that some of the oculomotor deficits that we observed after hemispheric lesions may be related to such a cognitive role of the cerebellum.

\section{A C K N O W LED G MENTS}

We thank Dr. Masao Ito (RIKEN BSI) for kind and helpful suggestions for preparation of the manuscript. We also thank Dr. GuoXiang Xiong (CREST, JST, and Children's Hospital of Pennsylvania) for technical suggestions on the surgical approach to the cerebellar hemispheric lobules.

\section{REFERENCES}

Barash S, Melikyan A, Sivakov A, Zhang M, Glickstein M, Thier P. Saccadic dysmetria and adaptation after lesion of the cerebellar cortex. J Neurosci 19: 10931-10939, 1999.

Bruce CJ, Goldberg ME. Primate frontal eye fields. I. Single neurons discharging before saccades. J Neurophysiol 53: 603-635, 1985.

Bruce CJ, Goldberg ME, Bushnell MC, Stanton GB. Primate frontal eye fields. II. Physiological and anatomical correlates of electrically evoked eye movements. J Neurophysiol 54: 714-734, 1985.

Catz N, Dicke PW, Thier P. Cerebellar complex spike firing is suitable to induce as well as stabilize motor learning. Curr Biol 15: 2179-2189, 2005.

Chubb MC, Fuchs AF. Contribution of y group of vestibular nuclei and dentate nucleus of cerebellum to generation of vertical smooth eye movements. J Neurophysiol 48: 75-99, 1982.
Dicke PW, Barash S, Uwe J, Thier P. Single-neuron evidence for a contribution of the dorsal pontine nuclei in both types of target-directed eye movements, saccade and smooth pursuit. Eur J Neurosci 19: 609-624, 2004.

Dieterich M, Bucher SF, Seelos KC, Brandt T. Cerebellar activation during optokinetic stimulation and saccades. Neurology 54: 148-155, 2000.

Dreher JC, Grafman J. The roles of the cerebellum and basal ganglia in timing and error prediction. Eur J Neurosci 16: 1609-1619, 2002.

Fujikado T, Noda H. Saccadic eye movements evoked by microstimulation of lobule VII of the cerebellar vermis of macaque monkeys. J Physiol 394: 573-594, 1987.

Glickstein M, Gerrits N, Kralj-Hans I, Mercier B, Stein J, Voogd J. Visual pontocerebellar projections in the Macaque. J Comp Neurol 349: 51-72, 1994.

Hayakawa Y, Nakajima T, Takagi M, Fukuhara N, Abe H. Human cerebellar activation in relation to saccadic eye movements: a functional magnetic resonance imaging study. Ophthalmologica 216: 399-405, 2002.

Heide W, Binkofski F, Seitz RJ, Posse S, Nitschke MF, Freund HJ, Kompf D. Activation of frontoparietal cortices during memorized triple-step sequences of saccadic eye movements: an fMRI study. Eur J Neurosci 13: 1177-1189, 2001.

Hiramatsu T, Ohki M, Kitazawa H, Xiong G, Kitamura T, Yamada J, Nagao S. Role of primate cerebellar lobulus petrosus of paraflocculus in smooth pursuit eye movement control revealed by chemical lesion. Neurosci Res 60: 250-258, 2008.

Hiramatsu T, Ohki M, Xiong G, Takeda T, Nagao S. Effects of chemical lesions of the lobulus petrosus of paraflocculus on the dynamic characteristics and adaptability of primate smooth pursuit eye movement. Soc Neurosci Abstr 766: 6, 2002.

Ito M. The Cerebellum and Neural Control. New York: Raven, 1984.

Jueptner M, Rijntjes M, Weiller C, Faiss JH, Timmann D, Mueller SP, Diener HC. Localization of a cerebellar timing process using PET. Neurology 45: 1540-1545, 1995.

Kase M, Miller DC, Noda H. Discharges of Purkinje cells and mossy fibers in the cerebellar vermis of the monkey during saccadic eye movements and fixation. $J$ Physiol 300: 539-555, 1980.

Kawashima R, Okuda J, Umetsu A, Sugiura M, Inoue K, Suzuki K, Tabuchi M, Tsukiura T, Narayan SL, Nagasaka T, Yanagawa I, Fujii T, Takahashi S, Fukuda H, Yamadori A. Human cerebellum plays an important role in memory-timed finger movement: an fMRI study. $J$ Neurophysiol 83: 1079-1087, 2000.

Keating EG. Frontal eye field lesions impair predictive and visually guided pursuit eye movements. Exp Brain Res 86: 311-323, 1991.

Keating EG, Pierre A, Chopra S. Ablation of the pursuit area in the frontal cortex of the primate degrades foveal but not optokinetic smooth eye movements. J Neurophysiol 76: 637-641, 1996.

Kitazawa H, Ohki M, Kitamura T, Yamada J, Nagao S. Characteristics of eye movements induced by microstimulation of the cerebellar hemisphere in primate. Soc Neurosci Abstr 297: 6, 2005.

Kyuhou SI, Matsuzaki R. Topographical organization of climbing fiber pathway from the superior colliculus to cerebellar vermal VI-VII in the cat. Neuroscience 45: 691-699, 1991.

Larsell $\mathbf{O}$, Jansen J. The Comparative Anatomy and Histology of the Cerebellum From Monotremes Through Apes. Minneapolis, MN: The University of Minnesota Press, 1970.

Leigh RJ, Zee DS. The Neurology of Eye Movements (4th ed.). Oxford, UK: Oxford Univ. Press, 2006.

Lindner A, Haarmeier T, Erb M, Grodd W, Thier P. Cerebrocerebellar circuits for the perceptual cancellation of eye-movement-induced retinal image motion. J Cog Neurosci 18: 1899-1912, 2006.

Lisberger SG, Fuchs AF. Role of primate flocculus during rapid behavioral modification of vestibuloocular reflex. I. Purkinje cell activity during visually guided horizontal smooth-pursuit eye movements and passive head rotation. J Neurophysiol 41: 733-763, 1978.

Lynch JC. Frontal eye field lesions in monkeys disrupt visual pursuit. Exp Brain Res 68: 437-441, 1987.

Lynch JC, Hoover JE, Strick PL. Input to the primate frontal eye field from the substantia nigra, superior colliculus, and dentate nucleus demonstrated by transneuronal transport. Exp Brain Res 100: 181-186, 1994.

Maekawa K, Simpson JI. Climbing fiber responses evoked in vestibulocerebellum of rabbit from visual system. J Neurophysiol 36: 649-666, 1973.

Mano N, Ito Y, Shibutani H. Saccade-related Purkinje cells in the cerebellar hemispheres of the monkey. Exp Brain Res 84: 465-470, 1991. 
Mano N, Ito Y, Shibutani H. Context dependent discharge characteristics of saccade-related Purkinje cells in the cerebellar hemispheres of the monkeys. Prog Brain Res 112: 423-430, 1996.

Marple-Horvat DE, Stein JF. Neuronal activity in the lateral cerebellum of trained monkeys, related to visual stimuli or to eye movements. J Physiol 428: 595-614, 1990.

May JG, Keller EL, Suzuki DA. Smooth-pursuit eye movement deficits with chemical lesions in the dorsolateral pontine nucleus of the monkey. $\mathrm{J} \mathrm{Neu}$ rophysiol 59: 952-977, 1988.

Miles FA, Fuller JH, Braitman DJ, Dow BM. Long-term adaptive changes in primate vestibuloocular reflex. III. Electrophysiological observations in flocculus of normal monkeys. J Neurophysiol 43: 1437-1476, 1981.

Mustari MJ, Fuchs AF, Wallman J. Response properties of dorsolateral pontine units during smooth pursuit in the rhesus macaque. $J$ Neurophysiol 60: $664-686,1988$

Nagao S. Different roles of flocculus and ventral paraflocculus for oculomotor control in the primate. Neuroreport 3: 13-16, 1992.

Nagao S, Hiramatsu T, Ohki M, Kitazawa H, Kitamura T and Yamada J. Anatomical characteristics of eye movement related primate cerebellar paravermis revealed by double-labeling method. Soc Neurosci Abstr 74: 10, 2003.

Nagao S, Kitamura T, Nakamura N, Hiramatsu T, Kitamura T, Yamada J. Differences of the primate flocculus and ventral paraflocculus in the mossy and climbing fiber input organization. J Comp Neurol 382: 480-498, 1997.

Nagao S, Kitazawa H. Adaptive modifications of post-saccadic smooth pursuit eye movements and their interaction with saccades and the vestibuloocular reflex in the primate. Neurosci Res 32: 157-169, 1998.

Newsome WT, Wurtz RH, Dursteler MR, Mikami A. Deficits in visual motion processing following ibotenic acid lesions of the middle temporal visual area of the macaque monkey. J Neurosci 5: 825-840, 1985.

Nitschke MF, Arp T, Stavrou G, Erdmann C, Heide W. The cerebellum in the cerebro-cerebellar network for the control of eye and hand movements-an fMRI study. Prog Brain Res 148: 151-164, 2005.

Noda H, Fujikado T. Topography of the oculomotor area of the cerebellar vermis in macaques as determined by microstimulation. J Neurophysiol 58 359-378, 1987.

Noda H, Mikami A. Discharges of neurons in the dorsal paraflocculus of monkeys during eye movements and visual stimulation. J Neurophysiol 56 1129-1146, 1986.

Ogawa T, Fujita M. Adaptive modifications of human postsaccadic pursuit eye movements induced by a step-ramp-ramp paradigm. Exp Brain Res 116: 83-96, 1997.

Ohtsuka K, Noda H. Discharge properties of Purkinje cells in the oculomotor vermis during visually guided saccades in the macaque monkey. J Neurophysiol 74: 1828-1840, 1995.

Ohki M, Kitazawa H, Hiramatsu T, Nagao S. Participation of hemispheric lobule VII in monkey smooth pursuit eye movement control. Neurosci Res Suppl 46: S164, 2003.

Ohyama T, Mauk MD. Latent acquisition of timed responses in cerebellar cortex. J Neurosci 21: 682-690, 2001.

Ono S, Das VE, Mustari MJ. Gaze-related response properties of DLPN and NRTP neurons in the rhesus macaque. J Neurophysiol 91: 2484-2500, 2004.

Optican LM, Zee DS, Miles FA. Floccular lesions abolish adaptive control of post-saccadic ocular drift in primates. Exp Brain Res 64: 596-598, 1986.

Rambold H, Churchland A, Selig Y, Jasmin L, Lisberger SG. Partial ablations of the flocculus and ventral paraflocculus in monkeys cause linked deficits in smooth pursuit eye movements and adaptive modification of the VOR. J Neurophysiol 87: 912-924, 2002.

Robinson DA. A method of measuring eye movement using a sclera search coil in a magnetic field. IEEE Trans Biomed Eng 10: 137-145, 1963.

Robinson FR, Fuchs AF. The role of the cerebellum in voluntary eye movements. Annu Rev Neurosci 24: 981-1004, 2001.

Robinson FR, Soetedjo R, Noto C. Distinct short-term and long-term adaptation to reduce saccade size in monkey. J Neurophysiol 96: 1030-1041, 2006.

Ron S, Robinson DA. Eye movements evoked by cerebellar stimulation in the alert monkey. J Neurophysiol 36: 1004-1022, 1973.

Sato H, Noda H. Posterior vermal Purkinje cells in the macaques responding during saccades, smooth pursuit, chair rotation and/or optokinetic stimulation. Neurosci Res 12: 583-595, 1992.
Shi D, Friedman HR, Bruce CJ. Deficits in smooth-pursuit eye movements after muscimol inactivation within the primate's frontal eye field. J Neurophysiol 80: 458-464, 1998.

Shidara M, Kawano K. Role of Purkinje cells in the ventral paraflocculus in short-latency ocular following responses. Exp Brain Res 93: 185-195, 1993.

Shutoh F, Ohki M, Kitazawa S, Itohara S, Nagao S. Memory trace of motor learning shifts transsynaptically from cerebellar cortex to nuclei for consolidation. Neuroscience 139: 767-777, 2006.

Soetedjo R, Fuchs AF. Complex spike activity of purkinje cells in the oculomotor vermis during behavioral adaptation of monkey saccades. $\mathrm{J} \mathrm{Neu}$ rosci 26: 7741-7755, 2006.

Stone LS, Lisberger SG. Visual responses of Purkinje cells in the cerebellar flocculus during smooth-pursuit eye movements in monkeys. I. Simple spikes. J Neurophysiol 63: 1241-1261, 1990.

Straube A, Scheuerer W, Eggert T. Unilateral cerebellar lesions affect initiation of ipsilateral smooth pursuit eye movements in humans. Ann Neurol 42: 891-898, 1997.

Suzuki DA, Keller EL. Visual signals in the dorsolateral pontine nucleus of the alert monkey: their relationship to smooth-pursuit eye movements. Exp Brain Res 53: 473-478, 1984.

Suzuki DA, Keller EL. The role of the posterior vermis of monkey cerebellum in smooth-pursuit eye movement control. I. Eye and head movement-related activity. J Neurophysiol 59: 1-18, 1988a.

Suzuki DA, Keller EL. The role of the posterior vermis of monkey cerebellum in smooth-pursuit eye movement control. II. Target velocity-related Purkinje cell activity. J Neurophysiol 59: 19-40, 1988b.

Suzuki DA, Noda H, Kase M. Visual and pursuit eye movement-related activity in the posterior vermis of monkey cerebellum. J Neurophysiol 46: 1120-1139, 1981.

Suzuki DA, Yamada T, Hoedema R, Yee RD. Smooth-pursuit eye movement deficits with chemical lesions in macaque nucleus reticularis tegmenti pontis. J Neurophysiol 82: 1178-1186, 1999.

Suzuki DA, Yamada T, Yee RD. Smooth-pursuit eye-movement-related neuronal activity in macaque nucleus reticularis tegmenti pontis. J Neurophysiol 89: 2146-2158, 2003.

Takagi M, Zee DS, Tamargo RJ. Effects of lesions of the oculomotor vermis on eye movements in primate: saccades. J Neurophysiol 80: 1911-1931, 1998

Takagi M, Zee DS, Tamargo RJ. Effects of lesions of the oculomotor cerebellar vermis on eye movements in primate: smooth pursuit. J Neurophysiol 83: 2047-2062, 2000.

Thielert CD, Thier P. Patterns of projections from pontine nuclei and the nucleus reticularis tegmenti pontis to the posterior vermis in the rhesus monkey: a study using retrograde tracers. J Comp Neurol 337: 113-126, 1993.

Thier P, Dicke PW, Haas R, Barash S. Encoding of movement time by populations of cerebellar Purkinje cells. Nature 405: 72-76, 2000.

Thier P, Koehler W, Buettner UW. Neural activity in the dorsolateral pontine nucleus of the alert monkey modulated by visual stimuli and eye movements. Exp Brain Res 70: 496-512, 1988.

Tracy JI, Faro SH, Mohamed FB, Pinsk M, Pinus A. Functional localization of a "Time Keeper" function separate from attentional resources and task strategy. Neuroimage 11: 228-242, 2000.

Voogd J, Barmack NH. Oculomotor cerebellum. Prog Brain Res 151: 231-268, 2006.

Xiong G, Hiramatsu T, Nagao S. Corticopontocerebellar pathway from the prearcuate region to hemispheric lobule VII of the cerebellum: an anterograde and retrograde tracing study in the monkey. Neurosci Lett 322: 173-176, 2002.

Xiong G, Nagao S. The lobulus petrosus of the paraflocculus relays cortical visual inputs to the posterior interposed and lateral cerebellar nuclei: an anterograde and retrograde tracing study in the monkey. Exp Brain Res 147: 252-263, 2002.

Yamada J, Noda H. Afferent and efferent connections of the oculomotor cerebellar vermis in the macaque monkey. J Comp Neurol 265: 224-241, 1987

Zee DS, Yamazaki A, Butler PH, Gucer G. Effects of ablation of flocculus and paraflocculus on eye movements in primate. J Neurophysiol 46: 878 899, 1981. 
Volume 101, February 2009

Ohki M, Kitazawa H, Hiramatsu T, Kaga K, Kitamura T, Yamada J, and Nagao S. Role of Primate Cerebellar Hemisphere in Voluntary Eye Movement Control Revealed by Lesion Effects. J Neurophysiol 101: 934-947, 2009. First published October 29, 2008; doi:10.1152/jn.90440.2009; http://jn.physiology.org/cgi/content/full/101/2/934.

This article was published in final form under an incorrect digital object identifier (DOI) number. The correct DOI is doi:10.1152/jn.90440.2008. 